UNIVERSIDADE DE SÃO PAULO

ESCOLA DE ENFERMAGEM

CASSIANE DEZOTI

A ENZIMA HEME OXIGENASE-1 NA LESÃO RENAL AGUDA OXIDATIVA PELA POLIMIXINA B.

SÃO PAULO

2008 


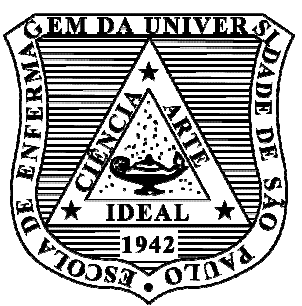

CASSIANE DEZOTI

\title{
A ENZIMA HEME OXIGENASE-1 NA LESÃO RENAL AGUDA OXIDATIVA PELA POLIMIXINA B.
}

\author{
Dissertação apresentada à Escola de \\ Enfermagem da Universidade de São Paulo, \\ para obtenção do Título de Mestre em \\ Enfermagem. \\ Área de concentração: \\ Enfermagem na Saúde do Adulto \\ Linha de Pesquisa: \\ Tecnologia na Saúde do Adulto \\ Orientadora: \\ Prof $^{a}$. Dr ${ }^{a}$. Maria de Fátima Fernandes Vattimo
}




\section{Catalogação na Publicação (CIP)}

Biblioteca "Wanda de Aguiar Horta"

Escola de Enfermagem da Universidade de São Paulo

Dezoti, Cassiane.

A enzima Heme Oxigenase-1 na lesão renal aguda oxidativa pela

Polimixina B. / Cassiane Dezoti. - São Paulo, 2008.

$64 \mathrm{p}$.

Dissertação (Mestrado) - Escola de Enfermagem da Universidade de São Paulo.

Orientadora: $\operatorname{Prof}^{\mathrm{a}}$ Dr $^{\mathrm{a}}$ Maria de Fátima Fernandes Vattimo.

1. Rim (lesões) 2. Antibióticos (toxicidade) 3. Enzimas Oxirredutoras 4. Antioxidantes 5. Polimixinas. I. Título. 


\section{FOLHA DE APROVAÇÃO}

Nome: CASSIANE DEZOTI

Título: A ENZIMA HEME OXIGENASE-1 NA LESÃO RENAL AGUDA OXIDATIVA PELA POLIMIXINA B.

Dissertação apresentada à Escola de Enfermagem da Universidade de São Paulo, para obtenção do título de Mestre em Enfermagem.

Aprovado em: I. 1

\section{Banca Examinadora}

Prof. Dr.

Julgamento:

Prof. Dr.

Julgamento:

Prof. Dr.

Julgamento:

Prof. Dr.

Julgamento:
Instituição:

Assinatura:

Instituição:

Assinatura:

Instituição:

Assinatura:

Instituição:

Assinatura: 


\section{Dedicatória}

Ao meu marido Fabricio, o qual amo muito e respeito. Obrigada por todo o seu amor e carinho e por estar comigo neste momento da minha vida. Aos meus pais Amaldo e Irany, pelo incentivo e valorização do saber.

Às minhas irmãs Cristiane e Claudiane pelo apoio carinhoso à distância 


\section{Agradecimentos}

À Prof ${ }^{a}$ Dr $^{a}$ Maria de Fátima Fernandes Vattimo, minha orientadora nesta dissertação, professora e conselheira. Uma mulher admirável que respeito muito e tenho como exemplo de vida.

À minha amiga Mirian Watanabe, pela dedicação incondicional em colaborar na produção deste trabalho e demais trabalhos do LEMA.

Às minhas amigas do LEMA, Cláudia, Carolina, Sara, Wanessa, Elisabete, Luciana, Juliana, Natália e Bruna. Obrigada meninas por vivenciarmos momentos alegres nos congressos e pelo apoio na coleta de dados deste trabalho.

Ao pesquisador Dro $^{\circ}$ Rildo Volpini. Obrigada pela colaboração.

Aos pesquisadores Denise e Celio do Laboratório de Biologia Vascular do Incor. Obrigada pela atenção e colaboração.

À equipe de patologistas do Dr. Fausone.

Às amigas Ruth, Michelle, Carolina Martins, Ana Paula, Carolina Santinho, Camila, Cristina e Eliane.

Aos novos membros da minha família: Carlos, Silvia, Flávia, Michel, Paula, Tíago, Caio, Bruna, Bianca, Rodrigo e Alexandre.

Aos amigos do Hospital Alemão Oswaldo Cruz.

Às enfermeiras Fátima, Luciene, Tânia e Edna.

À gerente Fátima Gerolim do Hospital Alemão Oswaldo Cruz.

À $\mathcal{N}$ eusa, amiga, protetora e mãe postiça deste laboratório. 
Dezoti C. A enzima Heme Oxigenase-1 na lesão renal aguda oxidativa pela Polimixina B. [dissertação] São Paulo (SP): Escola de Enfermagem da Universidade de São Paulo; 2008.

\section{RESUMO}

A Lesão Renal Aguda (LRA) tóxica se caracteriza por insulto tubular direto liberando espécies reativas de oxigênio (EROs) e estimulando processos pró-inflamatórios. Neste estudo foram investigadas a toxicidade do Sulfato de Polimixina B (PmxB), antibiótico catiônico usado para o tratamento de infecções por germes gram-negativos e a participação da enzima Heme Oxigenase-1 (HO-1), que tem efeito anti-apoptótico, antiinflamatório e outros. Foram utilizados ratos Wistar, adultos, machos, pesando entre 250-300g. Os animais foram distribuídos nos grupos: Salina (controle, animais que receberam $3 \mathrm{ml} / \mathrm{Kg}$ de $\mathrm{NaCl}$ 0,9\% intraperitoneal (i.p.), uma vez ao dia, 5 dias); PmxB (animais que receberam PmxB 40.000U/kg/dia, i.p., uma vez ao dia, 5 dias); Hemin (indutor da HO-1, $1 \mathrm{mg} / 100 \mathrm{~g}$, i.p., uma vez ao dia, 5 dias); Protoporfirina de Zinco (ZnPP) (inibidor da HO-1, $50 \mathrm{umol} / \mathrm{Kg}$, i.p., uma vez ao dia, 5odia); PmxB+Hemin; PmxB+ZnPP; PmxB+Hemin+ZnPP. Foram avaliados a função renal (FR) (clearance de creatinina, método de Jaffé), a excreção de peróxidos urinários (PU, FOX-2); TBARS urinários; tióis no tecido renal, atividade da catalase (AC) e foi realizada análise histológica no tecido renal. Os resultados mostraram que a $\mathrm{PmxB}$ induziu redução da $\mathrm{FR}$ com elevação de PU e TBARS, acompanhados por redução de AC e tióis: $O$ tratamento com indutor da $\mathrm{HO}-1$ reverteu a lesão pela $\mathrm{PmxB}$, com melhora da FR e dos parâmetros de peroxidação. A associação do PmxB com o inibidor ZnPP demonstrou aumento da área intersticial relativa (AIR) no tecido renal com achatamento das células tubulares e pontos de necrose no córtex renal. Os resultados diferenciados de FR e peroxidação lipídica, nas técnicas de mensuração utilizadas, confirmaram a participação da heme oxigenase como antioxidante desse modelo de toxicidade renal.

Palavras-Chave: Sulfato de Polimixina B, Lesão Renal Aguda, Heme oxigenase, Antioxidante. 
Dezoti C. The heme oxygenase-1 enzyme in oxidative acute kidney injury by polymyxin B. [Master degree] São Paulo (SP): Nursing School, University of São Paulo; 2008.

\section{ABSTRACT}

Toxic Acute Kidney Injury (AKI) consists on direct injury in the renal tubules liberating reactive oxygen species (ROS) and estimulating inflamatory processes. In this experimental study it was investigated the toxicity of Polymyxin B Sulfate $(\mathrm{PmxB})$, which is a cationic antibiotic used to treat gramnegative infections and the role of the heme oxygenase enzyme (HO-1), with anti-apoptotic and anti-inflamatory effects, in this injury. Adult male Wistar rats, weighing 250-300g were used. The animals were divided into the following groups: Saline (control, animals that received $3 \mathrm{ml} / \mathrm{Kg}$ of $\mathrm{NaCl} 0,9 \%$ intraperitoneal (i.p.), once a day, 5 days); PmxB (animals that received $\mathrm{PmxB} 40.000 \mathrm{U} / \mathrm{kg} / \mathrm{dia}$, i.p., once a day, 5 days); Hemin (HO-1 inducer, $1 \mathrm{mg} / 100 \mathrm{~g}$, i.p., once a day, 5 days); Zinc protoporphyrin (ZnPP) (HO-1 inhibitor, 50 umol/Kg, i.p., once a day, 5oday); PmxB+Hemin; PmxB+ZnPP; $\mathrm{PmxB}+$ Hemin+ZnPP. Renal Function (RF) (creatinine clearance, Jaffé method), urinary peroxides (UP, FOX-2), urinary TBARS, thiols in the renal tissue, activity of catalase enzyme (CA) and histology of renal tissue were performed. The results showed that $\mathrm{PmxB}$ reduced RF with increment in the UP and TBARS associated to the reduction in the CA and thiols. The HO-1 ameliorated these paramethers. The association $\mathrm{PmxB}$ with $\mathrm{ZnPP}$ increased relative intersticial area (RIA) of renal tissue with acute tubule necrosis in the renal cortex. The obtained data on RF and lipid peroxidation, with the methods used in the study, confirmed the antioxidant role of the heme oxygenase in this model of renal injury.

Key words: Polymyxin B Sulfate, Acute Kidney Injury, Heme oxygenase, Antioxidant. 


\section{LISTA DE ILUSTRAÇÕES}

Figuras 1, 2 e 3 - Mecanismo de ação do Sulfato de Polimixina $B^{9}$

Figura 4 - Esquema do sistema enzimático $\mathrm{HO}^{20}$

Gráfico 1 - Resultados referentes ao perfil oxidativo pelos métodos PU, AC, Tióis e TBARS dos grupos: Salina, Hemin, Protoporfirina de Zinco (ZnPP), PmxB, PmxB + Hemin, PmxB + ZnPP, PmxB + Hemin + ZnPP. São Paulo - 2008

Figura 5 - Cortes histológicos no tecido renal dos diversos grupos: Salina $(A)$; PmxB (B); Hemin (C); PmxB+Hemin(D); ZnPP (E) e PmxB+ZnPP (F).(Aumento 120x). 


\section{LISTA DE TABELAS}

Tabela 1 - Resultados de peso corporal e função renal global dos grupos: Salina, Hemin, Protoporfirina de Zinco (ZnPP), PmxB, PmxB + Hemin, PmxB + ZnPP, PmxB + Hemin + ZnPP. São Paulo, 2008.

Tabela 2 - Resultados referentes aos valores de peróxidos urinários dos grupos: Salina, Hemin, Protoporfirina de Zinco (ZnPP), PmxB, PmxB + Hemin, PmxB + ZnPP, PmxB + Hemin + ZnPP. São Paulo, 2008

Tabela 3 - Resultados referentes aos valores de TBARS urinários dos grupos: Salina, Hemin, Protoporfirina de Zinco (ZnPP), PmxB, PmxB + Hemin, PmxB + ZnPP, PmxB + Hemin + ZnPP. São Paulo - 2008

Tabela 4 - Resultados referentes à atividade de enzimas antioxidantes no tecido renal dos grupos: Salina, Hemin, Protoporfirina de Zinco (ZnPP), PmxB, PmxB + Hemin, PmxB + ZnPP, PmxB + Hemin + ZnPP. São Paulo-2008.

Tabela 5 - Resultados referentes aos valores da área intersticial relativa no tecido renal dos grupos: Salina, Hemin, Protoporfirina de Zinco $(Z n P P), P m x B, P m x B+$ Hemin, PmxB + ZnPP, PmxB + Hemin + ZnPP. São Paulo, 2008 


\section{LISTA DE ABREVIATURAS}

$\begin{array}{ll}\text { et al } & \text { e colaboradores } \\ \text { i.p. } & \text { intra-peritoneal } \\ \text { vs. } & \text { versus } \\ \text { cap. } & \text { capítulo (referente à publicação) } \\ \text { p. } & \text { página } \\ \text { ed. } & \text { edição } \\ \text { v. } & \text { volume }\end{array}$




\section{LISTA DE SÍMBOLOS}

$\mathrm{ml}$
$\mathrm{mg}$
$\mathrm{dl}$
$\mathrm{N}$
$\mathrm{M}$
$\mathrm{Nm}$
$\mu \mathrm{m}$
$\mathrm{mm}$
$\mu l$
$\mathrm{nmol}$
$\mu \mathrm{mol}$
$\mathrm{g}$
$\mathrm{nmolg} / \mathrm{Cr}$
${ }^{0} \mathrm{C}$
$\mathrm{p}$
$=$
+
$\mathrm{n}$
$<$
$\%$

mililitro

miligrama

decilitro

normal

molar

nanômetro

micromolar

milimolar

microlitro

nanomol

micromol

grama

nanomol por grama de creatinina

graus centígrados

nível de significância do resultado estatístico

igual

mais

número de animais estudados

menor

porcentagem 


\section{LISTA DE SIGLAS}

LRA

HO-1

EROs

PmxB

ZnPP

FR

FOX-2

$A C$

TBARS

PU

CO

$\mathrm{HO}-2$

HO-3

eNOS

iNOS

ATP

UTI

NTA

$\mathrm{Na} / \mathrm{KATPase}$

TNF- $\alpha$

IL-1

IL-2

IL-8

ICAM-1

$\mathrm{O}_{2}$

LEMA

MDA

Clcr

COBEA

CEEA

$\mathrm{NaCl}$

PBS

CU lesão renal aguda

heme oxigenase-1

espécies reativas de oxigênio

sulfato de polimixina $B$

protoporfirina de zinco

função renal

xilenol laranja versão-2

atividade da catalase

substâncias reativas com ácido tiobarbitúrico

peróxidos urinários

monóxido de carbono

heme oxigenase 2

heme oxigenase 3

oxido nítrico síntase endotelial

oxido nítrico redutase induzível

adenosina tri-fosfato

unidade de terapia intensiva

necrose tubular aguda

sódio potássio ATPase

fator de necrose tumoral- $\alpha$

interleucina-1

interleucina-2

interleucina-8

molécula de adesão intercelular-1

molécula de oxigênio

laboratório experimental de modelos animais

malondealdeído

clearance de creatinina

colégio brasileiro de experimentação animal comissão de ética em experimentação animal

cloreto de sódio

tampão trifosfato

creatinina urinária 


\begin{tabular}{|c|c|}
\hline $\mathrm{CP}$ & creatinina plasmática \\
\hline$\cup$ & volume urinário \\
\hline $\mathrm{H}_{2} \mathrm{O}_{2}$ & peróxido de hidrogênio \\
\hline $\mathrm{OH}^{-}$ & radical hidroxila \\
\hline $\mathrm{O}_{2}^{-}$ & radical superóxido \\
\hline SOD & superóxido dismutase \\
\hline $\mathrm{NADPH}$ & nicotinamida adenina dinucleotídeo de fosfato \\
\hline GSH & glutationa \\
\hline GSSG & glutationa oxidada \\
\hline $\mathrm{H}_{2} \mathrm{O}$ & água \\
\hline $\mathrm{H}^{+}$ & íon de hidrogênio \\
\hline $\mathrm{O}_{2}$ & oxigênio \\
\hline $\mathrm{Cu}^{+}$ & íon cobre \\
\hline $\mathrm{Fe}^{+2}$ & íon ferro \\
\hline $\mathrm{H}_{2} \mathrm{SO}_{4}$ & ácido sulfúrico \\
\hline HPLC & sistema de cromoterapia de alta pressão \\
\hline TCA & ácido tricloroacético \\
\hline DTPA & dietilenotriamina-N,N,N',N'-pentaacetato \\
\hline DTNB & 5,5’-ditiobis (2-ácido nitrobenzóico) \\
\hline $\mathrm{BHT}$ & $2[6]$ - di-ter-butil-p-cresol \\
\hline $\mathrm{HCl}$ & ácido clorídrico \\
\hline EDTA & ácido etilenedinitrolo tetraacético \\
\hline DAB & diaminobenzidine tetrahydrochoride -D5637 \\
\hline EEUSP & $\begin{array}{l}\text { Escola de Enfermagem da Universidade de } \\
\text { São Paulo }\end{array}$ \\
\hline PC & peso corporal \\
\hline DNA & ácido desoxirribonucleico \\
\hline NO & óxido nítrico \\
\hline CoPP & protoporfirina de cobalto \\
\hline SnPP & protoporfirina de estanho \\
\hline
\end{tabular}




\section{SUMÁRIO}

1 INTRODUÇÃO

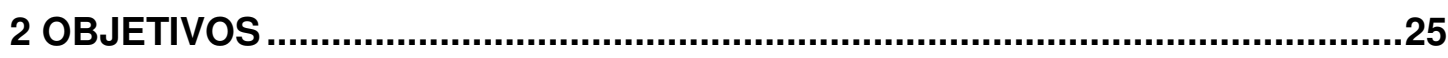

3 MATERIAIS E MÉTODOS......................................................................27

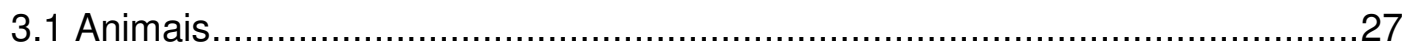

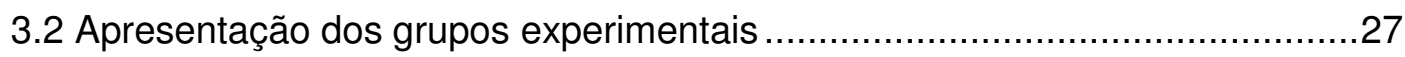

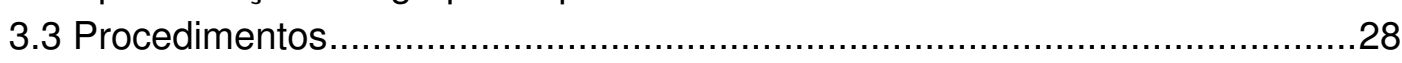

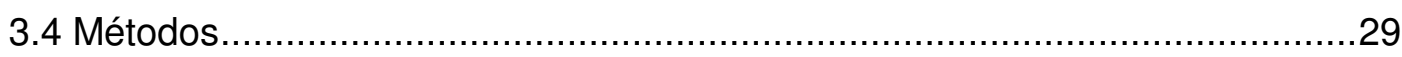

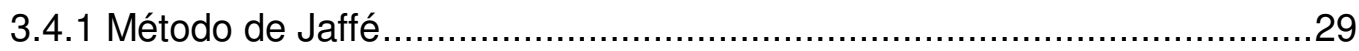

3.4.2 Método FOX-2 para peróxidos urinários ...........................................30

3.4.3 Dosagem de TBARS (Substâncias reativas com ácido tiobarbitúrico

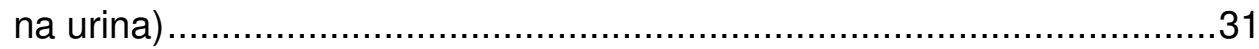

3.4.4 Análise de tióis solúveis não protéicos no tecido renal .........................32

3.4.5 Atividade da catalase no tecido renal ................................................33

3.4.6 Análise histológica e morfométrica ....................................................34

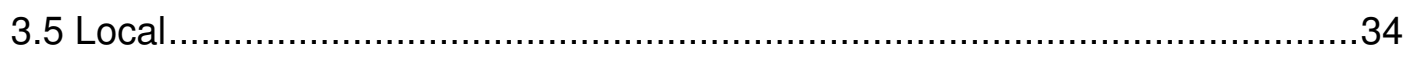

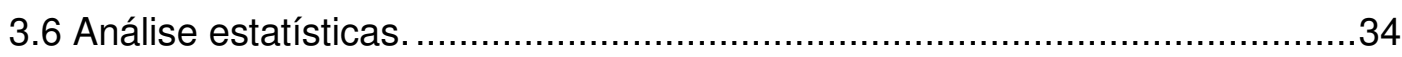

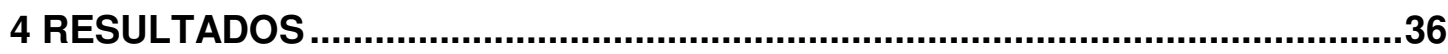

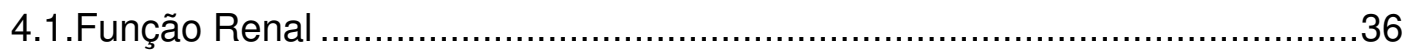

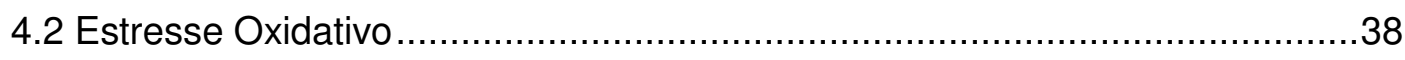

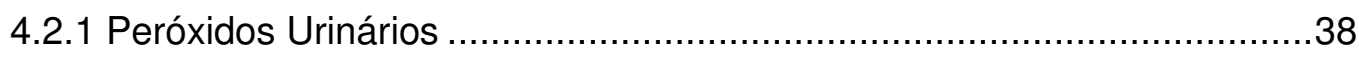

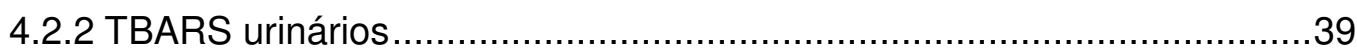

4.2.3 Enzimas antioxidantes: Atividade da Catalase (AC) e tióis solúveis não protéicos no tecido renal. ......................................................40

4.3 Análise histológica e morfométrica do tecido renal .................................42

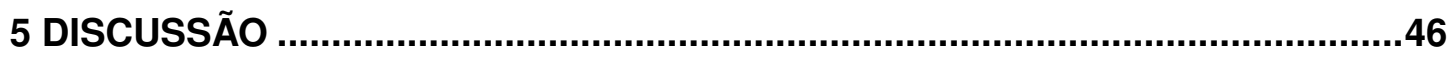

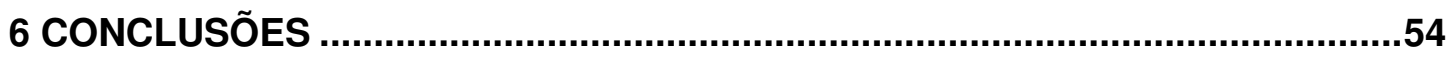

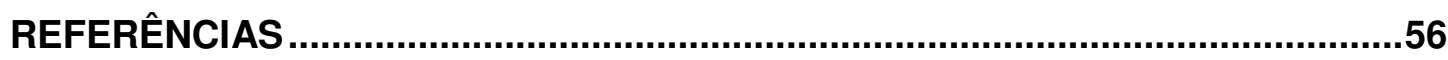

ANEXO 


\section{INTRODUÇÃO}

A lesão renal aguda (LRA) tóxica induz uma combinação variável de vasoconstrição intrarenal, toxicidade tubular direta ou obstrução intratubular ${ }^{(1,2)}$. A manutenção da hipóxia decorrente da vasoconstrição resulta na depleção de adenosina tri-fosfato (ATP) e liberação de espécies reativas de oxigênio (EROs), estimulando processos pró-inflamatórios. Simultâneamente, proteínas conhecidas como heat shock 32 atuam na renoproteção frente à lesão resultante do uso de drogas nefrotóxicas utilizadas na prática clínica. Entre essas proteínas destaca-se o efeito citoprotetor da enzima heme oxigenase-1 $(\mathrm{HO}-1)^{(3)}$.

A LRA é uma condição relativamente comum em Unidades de Terapia Intensiva (UTI) e ocorre em 20-30\% dos pacientes graves, sendo que 6\% requerem terapia de substituição renal ${ }^{(4)}$. O desenvolvimento da LRA nesse contexto está associado ao aumento da mortalidade, internação hospitalar prolongada e elevação nos custos e recursos da saúde ${ }^{(5)}$.

A complexa natureza das doenças graves freqüentemente exige o uso de múltiplas drogas terapêuticas, as quais, associadas ou não, apresentam risco para nefrotoxicidade ${ }^{(5)}$.

Enquanto em muitos dos casos a etiologia da LRA é multifatorial (sepsis, isquemia, hipoperfusão), estudos epidemiológicos recentes mostraram que drogas nefrotóxicas contribuíram para a ocorrência de LRA severa em $19-25 \%$ dos pacientes críticos ${ }^{(6,7)}$.

O tratamento clínico para infecções por bactérias gram-negativas multi-resistentes em pacientes graves contribui para um número crescente de LRA tóxica induzida pelo uso de drogas como o sulfato de polimixina $B$

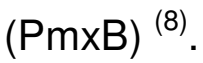

A PmxB pode induzir nefrotoxicidade com necrose tubular aguda (NTA), azotemia e aumento da concentração da creatinina sérica ${ }^{(9)}$. A ação terapêutica da PmxB se caracteriza por uma atividade surfactante, pois possui uma estrutura molecular composta por uma região hidrofílica que 
interage com lipídios da membrana plasmática externa, e outra região com carga positiva que interage com água ou com resíduos negativos. Esse mecanismo permite que esses peptídeos, chamados catiônicos, estabeleçam ligação com membranas compostas por moléculas anfipáticas negativas como as das bactérias e também as humanas. Ocorre, portanto, um aumento da permeabilidade da membrana, resultando no influxo de cátions, ânions e água, provocando a lise celular ${ }^{(10,11)}$. (Figuras 1,2 e 3)
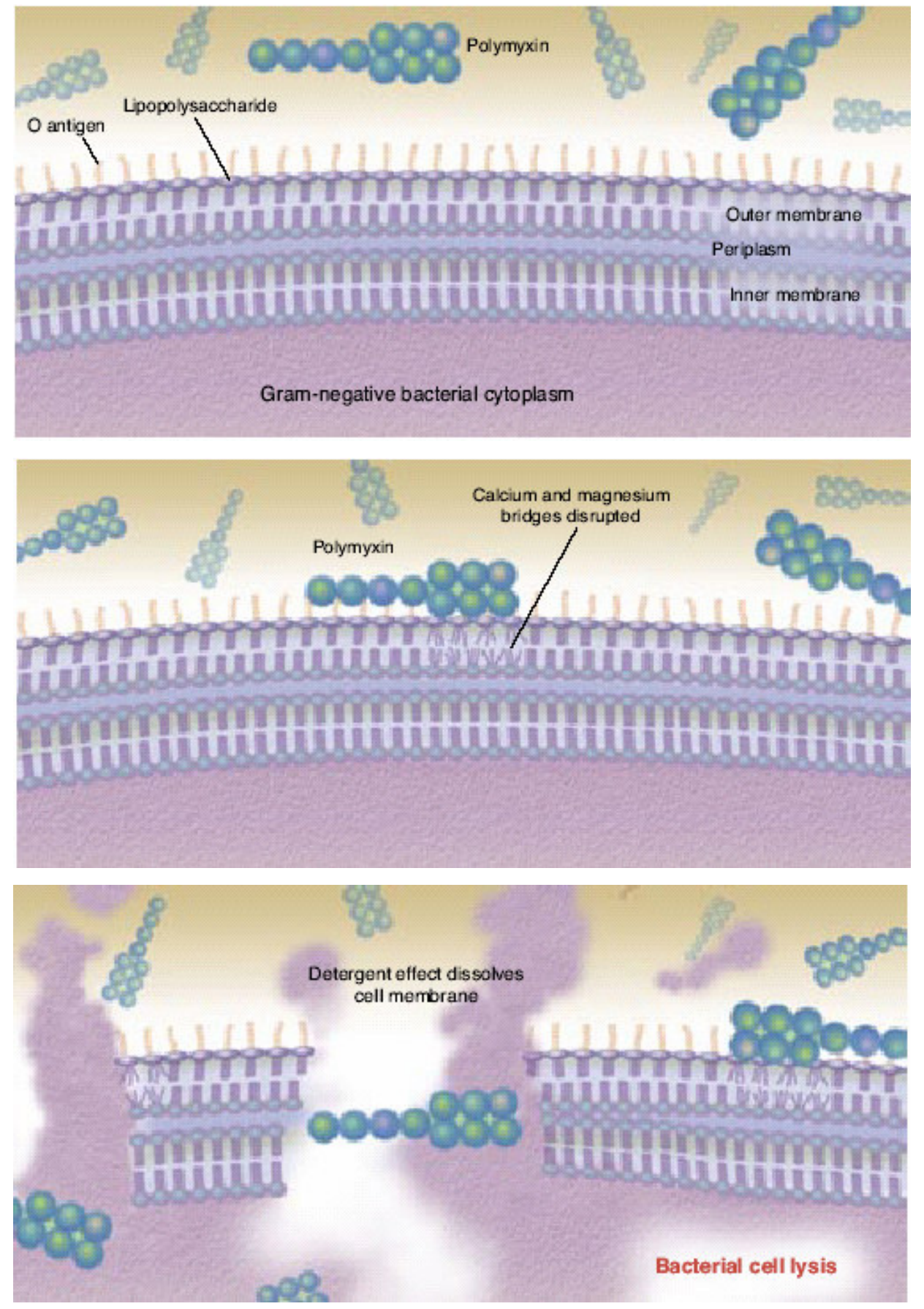

Figuras 1, 2 e 3 - Mecanismo de ação do Sulfato de Polimixina $\mathrm{B}^{(9)}$. 
Os números de grupos catiônicos nas moléculas da $\mathrm{PmxB}$ determinam a facilidade com que essas drogas são transportadas através da membrana celular e é um importante determinante de toxicidade. A deposição dos polipeptídios catiônicos nos lisossomos interfere nas funções celulares como a síntese de proteína e função mitocondrial, induzindo a morte celular ${ }^{(5)}$.

Inúmeros são os mecanismos de nefrotoxicidade que envolvem alterações glomerulares, tubulares e endoteliais. A vulnerabilidade renal a ação de drogas se deve ao rico suprimento sanguíneo renal (25\% do débito cardíaco) possibilitando a alta concentração de toxinas no interstício medular renal por meio de mecanismo contra-corrente ${ }^{(1,2)}$.

A administração de altas doses da droga pode desencadear desequilíbrio hemodinâmico na microcirculação renal, com eleveção dos níveis de cálcio intracelular, diminuição da produção do óxido-nitrico derivado do endotélio que corroboram para uma vasoconstrição medular causando nefrose osmótica ${ }^{(12)}$.

Por outro lado, a hipoperfusão tubular se instala com alterações na polaridade das células como o deslocamento da bomba $\mathrm{Na} / \mathrm{KATPase}$ da membrana basolateral para o domínio apical. $O$ enfraquecimento no transporte de sódio e água fora do lúmen do túbulo proximal aumentam as atividades de feedback tubuloglomerular distal prolongando a vasoconstrição intrarenal $^{(12)}$.

Os mecanismos de toxicidade direta ativam a cascata de resposta inflamatória via produção de leucócitos na microvasculatura renal. Concomitantemente, com a disfunção endotelial são gerados inúmeros mediadores pró-inflamatórios, os quais representam uma resposta de adaptação ao desequilíbrio, com o desbalanço entre fatores vasoconstritores e vasodilatadores ${ }^{(13)}$. A lesão endotelial ou a alteração da função endotelial são resultantes da vasoconstrição local que favorece o edema celular, 0 aumento da expressão das moléculas de adesão e conseqüentemente a ativação leucócito-endotelial. A despolarização celular no citoesqueleto induz 
Cassiane Dezoti

a expressão de inúmeras espécies vasoativas e manifesta uma reatividade vascular aberrante com o aumento do tônus basal e prejuízo na autoregulação do fluxo sangüíneo renal, prevalecendo a ação de vasoconstritores como a endotelina ${ }^{(1,2,13)}$.

A resposta inflamatória e a vasoconstrição da microvasculatura resultam da geração de EROs caracterizando o desequilíbrio redox ou peroxidação lipídica. As EROs representam a produção intracelular desbalanceada de alguns agentes intermediários nocivos à integridade de várias biomoléculas incluindo proteínas, lipídios e DNA ${ }^{(12)}$.

As EROs podem lesar as células do epitélio tubular por via direta ou por meio da ativação de processos inflamatórios. A resposta inflamatória é mediada pelo aumento da expressão de inúmeras citocinas que incluem o fator de necrose tumoral (TNF- $\alpha$ ), o interferon-y e interleucinas (IL-1, IL-2, IL8). Essas citocinas, juntamente com as EROs e os eicosanóides, ativam os leucócitos e aumentam a expressão de moléculas de adesão endotelial como as ICAM-1, selectina $P$ e E. A ativação das células endoteliais e de leucócitos resulta na geração de enzimas proteolíticas e de citocinas que iniciam o processo de apoptose e necrose celular. Sendo assim um mecanismo de retroalimentação dinâmica perdura mesmo após a interrupção do insulto inicial ${ }^{(2,14)}$.

As EROs comprometem a vitalidade celular, a ação de fatores de crescimento e proliferação celular, o reparo e regeneração tecidual, os processos inflamatórios e imunológicos e a regulação de vários sistemas como o hemodinâmico, homeostático e vascular ${ }^{(15)}$.

Por outro lado, as EROs também têm um papel fisiológico, e quando produzidas de forma contínua em pequenas quantidades no metabolismo oxidativo microssomal se caracterizam pelo radical superóxido $\left(\mathrm{O}_{2}{ }^{-}\right)$, o não radical peróxido de hidrogênio $\left(\mathrm{H}_{2} \mathrm{O}_{2}\right)$ e o radical hidroxila $\left(\mathrm{OH}^{-}\right)^{(1)}$.

Apesar da conotação tóxica, os baixos níveis de EROs são necessários para a manutenção de funções celulares que incluem a modulação de várias quinases e a ativação de fatores de transcrição envolvidos com a regulação gênica de algumas proteínas. O desequilíbrio 
entre esses agentes oxidantes e enzimas antioxidantes endógenas, em favor dos primeiros, é que representa o mecanismo redox ${ }^{(16)}$.

A homeostase celular é mantida devido à existência de mecanismos de defesa antioxidantes que são determinados por várias enzimas antioxidantes endógenas, destacando-se a superóxido dimutase (SOD) para a eliminação do radical $\mathrm{O}_{2}^{-}$(equação 1 ), a catalase e a glutationa peroxidase que são relacionadas com a eliminação do $\mathrm{H}_{2} \mathrm{O}_{2}$ e peróxidos orgânicos (equações 2 e 3$)^{(2,16)}$.

$$
\begin{gathered}
\mathrm{O}_{2} \cdot{ }^{-}+\mathrm{O}_{2} \cdot+2 \stackrel{\mathrm{H}^{+} \text {SOD }}{\longrightarrow} \mathrm{H}_{2} \mathrm{O}_{2}+\mathrm{O}_{2} \text { (eq.1) } \\
\mathrm{H}_{2} \mathrm{O}_{2}+\mathrm{H}_{2} \mathrm{O}_{2} \stackrel{\text { catalase }}{\longrightarrow} 2 \mathrm{H}_{2} \mathrm{O}+\mathrm{O}_{2} \text { (eq.2) } \\
\mathrm{H}_{2} \mathrm{O}_{2}+2 \mathrm{GSH} \stackrel{\text { glutationa peroxidase / NADPH }}{\longrightarrow} 2 \mathrm{H}_{2} \mathrm{O}+\mathrm{GSSG} \text { (eq.3) }
\end{gathered}
$$

$\mathrm{O} \mathrm{O}_{2}^{-\cdot}$ pode reagir com intermediário $\mathrm{H}_{2} \mathrm{O}_{2}$ que gera o radical hidroxila (reação de Haber-Weiss) ${ }^{(15)}$ :

$$
\mathrm{O}_{2}^{-{ }^{-}}+\mathrm{H}_{2} \mathrm{O}_{2} \longrightarrow \mathrm{O}_{2}+\mathrm{OH}+\mathrm{OH}^{-} \text {(eq. 4) }
$$

A outra forma de geração do radical hidroxila é a reação de Fenton que envolve $\mathrm{H}_{2} \mathrm{O}_{2}$ e metais de transição $\mathrm{Fe}^{+2}$ ou $\mathrm{Cu}^{+2}$ e oxigênio ${ }^{(16)}$ :

$$
\mathrm{H}_{2} \mathrm{O}_{2}+\mathrm{Cu}+/ \mathrm{Fe}^{+2} \longrightarrow \mathrm{OH}+\mathrm{OH}^{-}+\mathrm{Cu}^{+2} / \mathrm{Fé}^{+3}(\text { eq. 5) }
$$

$\mathrm{O}_{2} \mathrm{O}_{2}$ tem alta habilidade de penetrar nas membranas biológicas, sendo um sinalizador intracelular de moléculas. Uma vez produzido em excesso, $\mathrm{O}_{2} \mathrm{O}_{2}$ ativa o sistema enzimático antioxidante, a saber, catalase, glutationa peroxidase e superóxido dismutase ${ }^{(12)}$.

A glutationa peroxidase é considerada uma enzima de alta efetividade entre as enzimas antioxidantes, pois atua contra os peróxidos lipídicos e 0 $\mathrm{H}_{2} \mathrm{O}_{2}$ utilizando a NADPH (nicotinamida adenina dinucleotídeo de fosfato), como demonstrado anteriormente como espécie redutora. A glutationa peroxidase é conhecida como o antioxidante endógeno de maior peso molecular do citoplasma com presença significativa no rim $^{(17)}$. 
O desequilíbrio entre a formação de EROs e antioxidantes endógenos desencadeia mecanismos de proteção celular como a enzima heme oxigenase $(\mathrm{HO})$.

A HO é responsável pela degradação do grupo heme. A heme é uma ferro-protoporfirina derivada de várias heme-proteínas como a hemoglobina, a mioglobulina, o citocromo mitocondrial e microssomal, as prostaglandinas endoperóxido sintase, a óxido nítrico sintase, algumas oxigenases, como a catalase, e as peroxidases ${ }^{(15)}$. As células que contém o grupo heme exercem um papel importante na manutenção de funções celulares incluindo a oxigenação, a respiração e a sinalização celular ${ }^{(18)}$.

O sistema HO degrada o grupo heme em ferro, facilitando a conversão de heme para biliverdina. Essa conversão ocorre com a abertura do anel de heme na presença de NADPH, liberando o ferro e monóxido de carbono (CO). Subseqüentemente, a biliverdina é convertida em bilirrubina sob ação da enzima biliverdina redutase. A bilirrubina é considerada um antioxidante importante, pois age como seqüestrador de radicais peroxidonitrito, além de inibir a peroxidação lipídica em outras etapas ${ }^{(19)}$. (Figura 4)

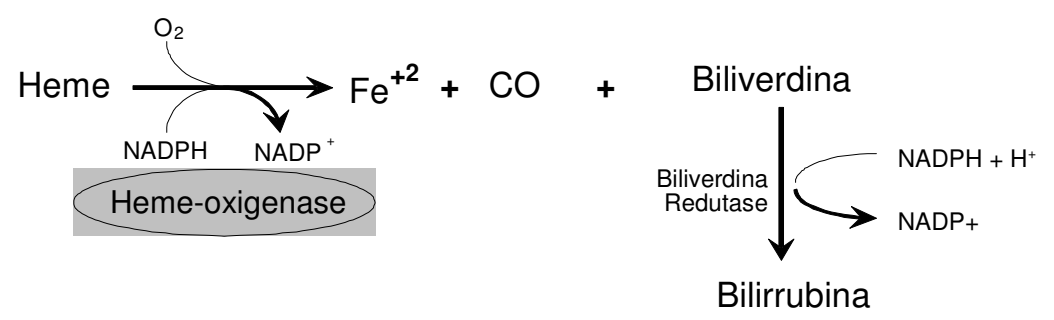

Figura 4 - Esquema do sistema enzimático $\mathrm{HO}{ }^{(20)}$.

A HO tem três isoformas: a HO-1, HO-2 e HO-3.

A isoforma induzível $\mathrm{HO}-1$ é bastante estudada como um sistema citoprotetor efetivo. A atividade de $\mathrm{HO}-1$ como antioxidante é o primeiro mecanismo a ser considerado. $\mathrm{O}$ aumento da atividade da $\mathrm{HO}-1$ resulta em maior degradação do grupo heme, reduzindo a formação desse próoxidante, potencialmente tóxico para a célula ${ }^{(21)}$. A degradação de heme 
Cassiane Dezoti

pelo sistema enzimático $\mathrm{HO}$ induz também a síntese de ferritina, a qual seqüestra o ferro livre, impedindo a sua participação na lesão oxidativa. A ferritina é uma proteína que seqüestra e catalisa o ferro intracelular e responde paralelamente à elevação dos níveis de $\mathrm{HO}{ }^{(22)}$.

A enzima $\mathrm{HO}-1$ está associada a vários processos patológicos, incluindo LRA. A indução de HO-1 previamente com hemoglobina em modelo de LRA associado à rabdomiólise reduziu consideravelmente a taxa de mortalidade ${ }^{(23)}$. Em estudo com modelo de LRA nefrotóxica induzida por cisplatina, o tratamento com inibidor químico $\mathrm{HO}-1$ demonstrou piora significativa da função renal (FR) em animais ${ }^{(24)}$.

$\mathrm{O}$ efeito antioxidante protetor demonstrado para a $\mathrm{HO}-1$ parece se assemelhar a outros resultados descritos anteriormente para SOD, glutationa peroxidase e catalase ao serem ativados por substâncias como vitamina $\mathrm{E}$, vitamina $\mathrm{C}$, thymoquinone e $\mathrm{N}$-acetilcisteína que preveniram a nefrotoxicidade induzida por gentamicina, cisplatina e radiocontraste ${ }^{(25,26,27,28,29)}$.

Estudos experimentais recentes de modelos de LRA por radiocontraste demonstraram renoproteção via indução de HO-1. O aumento do metabolismo heme foi associado ao aumento do eNOS e diminuição do iNOS, promovendo vasodilatação da microvasculatura renal. A resposta de redução do estresse oxidativo foi associada aos seqüestradores de radicais livres como a bilirrubina e monóxido de carbono ${ }^{(30)}$.

Em estudos sobre a nefrotoxicidade por glicerol, a indução da HO-1 promoveu redução de moléculas inflamatórias e preservou a função renal ${ }^{(31)}$.

Estudos realizados no Laboratório Experimental de Modelos Animais (LEMA) - EEUSP demonstraram renoproteção da lesão oxidativa na LRA isquêmica em ratos com a indução da enzima HO-1. A melhora da FR e o aumento dos níveis dos tióis, catalase com redução de malondealdeído (MDA) demonstrou a participação dessa enzima no desequilíbrio redox induzido pelo modelo de clampeamento renal por 30 minutos $^{(32)}$. 
O efeito citoprotetor da indução da heme oxigenase também foi confirmado em modelos em que se estabeleceu a toxicidade da PmxB em células $\mathrm{LLCPK}_{1}$. Aquele estudo demonstrou que a indução da HO-1 reduziu apoptose e otimizou a viabilidade daquelas células na presença de $\mathrm{PmxB}^{(33)}$.

O re-uso da $\mathrm{PmxB}$ nos dias atuais emergiu em resposta ao crescimento das infecções por microorganismos multiresistentes. A alta resistência bacteriana, tanto mutacional quanto adaptativa, associada ao avanço de situações em que a imunossupressão terapêutica se tornou mais expressiva como nos transplantes abriram espaço para iniciativas farmacológicas mais agressivas. Esse fato reforçou a criação de novos agentes ou a recaptação de fármacos cujo uso clínico estava restrito em decorrência de críticas relacionadas aos efeitos adversos, como a PmxB.

A hipótese deste estudo é que a $\mathrm{HO}-1$ possa estar relacionada com a lesão renal induzida pela polimixina $B$ e que esse efeito tenha como componente fisiopatológico o desequilíbrio redox. O estudo avança na tentativa de vislumbrar alternativas terapêuticas futuras para essa LRA. 


\section{Objetivos}




\section{OBJETIVOS}

- Avaliar o efeito da PmxB sobre a FR dos animais, por meio do clearance de creatinina (Clcr);

- Verificar o efeito do indutor (Hemin) e do inibidor (ZnPP) da HO-1 sobre a FR de ratos tratados com o $\mathrm{PmxB}$, por meio do Clcr;

- Verificar o efeito do indutor e do inibidor da HO-1 sobre a peroxidação lipídica renal dos ratos tratados com PmxB (TBARS, FOX-2, Tióis, AC);

- Realizar análise histológica do tecido renal. 


\section{Materiais e Métodos}




\section{MATERIAIS E MÉTODOS}

\subsection{ANIMAIS}

Todos os procedimentos realizados neste estudo estão de acordo com os Princípios Éticos de Experimentação Animal adotado pelo Colégio Brasileiro de Experimentação Animal (COBEA) e foram aprovados pela Comissão de Ética em Experimentação Animal (CEEA). (anexo)

Foram utilizados ratos da raça Wistar, machos, adultos, pesando entre 250-300g. Os animais dos diversos grupos foram mantidos com livre acesso à água e alimentos e permaneceram em condições térmicas com ciclos alternados de dia e noite.

\subsection{APRESENTAÇÃO DOS GRUPOS EXPERIMENTAIS}

Os animais foram agrupados nos seguintes protocolos:

\section{Nefrotoxicidade}

- Salina (controle): animais que receberam $3 \mathrm{ml} / \mathrm{Kg}$ de $\mathrm{NaCl}$ 0,9\% intraperitoneal (i.p.), uma vez ao dia, por 5 dias;

- PmxB: animais que receberam PmxB (Badford labs-USA) $40.000 \mathrm{U} / \mathrm{kg} / \mathrm{dia}$, i.p., uma vez ao dia, por 5 dias.

HO

Os animais receberam o inibidor ou o indutor da $\mathrm{HO}$ por via i.p.

O Hemin é um composto de protoporfirina com íon trivalente $\left(\mathrm{Fe}^{+3}\right)$ sendo considerado um forte indutor da $\mathrm{HO}^{(34)}$.

A protoporfirina de zinco (ZnPP) é um inibidor seletivo da HO. As famílias compostas de porfirinas inibem a atividade de HO-1 com alta especificidade $^{(35)}$. 
- Hemin: animais que receberam Hemin (Hemin-1g, Fluka CheminSigma Aldrich; Switzerland) 1mg/100g, i.p., uma vez ao dia, por 5 dias;

- PmxB + Hemin: animais que receberam PmxB 40.000U/kg/dia, i.p., + Hemin 1mg/100g, i.p., uma vez ao dia, por 5 dias;

- ZnPP: animais que receberam ZnPP (Porphirine Zinc, SyntheticFluka Chemin-Sigma Aldrich; Switzerland) 50 umol/Kg, i.p., apenas uma vez no $5^{\circ}$ dia, 1 hora antes da PmxB;

- PmxB + ZnPP: animais que receberam PmxB 40.000U/kg/dia, i.p., uma vez ao dia, por 5 dias + ZnPP $50 u m o l / K g$, i.p., apenas uma vez no $5^{\circ}$ dia, 1 hora antes da PmxB;

- $\mathrm{PmxB}+$ Hemin + ZnPP: animais que receberam PmxB 40.000U/kg/dia, i.p. + Hemin 1mg/100mg, i.p., uma vez ao dia por 5 dias e ZnPP 50umol/Kg, i.p., apenas uma vez no $5^{\circ}$ dia, 1 hora antes da PmxB.

\subsection{PROCEDIMENTOS}

Ao final dos protocolos, os animais foram colocados em gaiola metabólica para a coleta de urina de 24 horas. Após esse período foram retirados da gaiola metabólica. Cada animal foi mantido anestesiado com Thiopentax® (Cristália-Brasil) (tiopental sódico: 20-30mg/kg) e foi realizada a coleta de sangue da aorta abdominal para a mensuração da creatinina sérica.

O rim direito de cada animal foi retirado e imediatamente resfriado para estudos posteriores de mensuração das enzimas antioxidantes.

O rim esquerdo foi perfundido com $100 \mathrm{ml}$ da solução salina com tampão fosfato (PBS) e $60 \mathrm{ml}$ de paraformaldeído a 4\%, posteriormente resfriado a $4^{\circ} \mathrm{C}$ durante 2 horas. Ao término desse tempo, imerso em solução de Bouin por 4 horas em temperatura ambiente. O tecido renal foi então submetido a sucessivos banhos de álcool 70\% para eliminar o ácido 
pícrico, desidratado e embebido em parafina. Este material foi preparado para realização das lâminas de histologia.

Ao final do experimento o animal foi sacrificado segundo as normas éticas para manuseio de animais em laboratório.

\subsection{MÉTODOS}

\subsubsection{Método de Jaffé}

A função renal foi avaliada por meio do clearance de creatinina $\left(\mathrm{Cl}_{\text {creat }}\right)^{(36)}$.

A dosagem de creatinina foi determinada pelo método de colorimetria.

Para os cálculos da filtração glomerular se utilizou a seguinte fórmula:

$$
\mathrm{Cl}_{\text {creat }}=\frac{\mathrm{CU} \times \mathrm{V}}{\mathrm{CP}}
$$

Sendo $\mathrm{CU}=$ creatinina urinária em $\mathrm{mg} / \mathrm{dl}, \mathrm{V}=$ volume urinário em $\mathrm{ml} / \mathrm{min}$ e CP = creatinina plasmática em $\mathrm{mg} / \mathrm{dl}$.

\section{Dosagem de creatinina plasmática}

A primeira etapa para mensuração da creatinina plasmática consistiu na desproteinização do plasma. Neste processo, $0,5 \mathrm{ml}$ de plasma diluído em $1,5 \mathrm{ml}$ de água destilada (1:5) recebeu $0,25 \mathrm{ml}$ de tungstato de sódio $10 \%$ e 0,25 de ácido sulfúrico 0,75 N. A solução final foi homogeneizada e centrifugada durante 10 minutos a 5000 r.p.m. O sobrenadante $(1,5 \mathrm{ml})$ foi retirado para etapa seguinte.

Foram adicionados ao sobrenadante $0,3 \mathrm{ml}$ de hidróxido de sódio 0,75N e 0,3 $\mathrm{ml}$ de ácido pícrico 0,036M. A solução permaneceu em repouso por 20 minutos em temperatura ambiente após a homogeneização. A leitura para a dosagem da creatinina se procedeu em espectrofotômetro de absorbância em 520nm. Os resultados foram expressos em mg/dl. 
A dosagem de creatinina urinária reuniu $0,05 \mathrm{ml}$ da amostra de urina diluída em $5 \mathrm{ml}$ de água destilada(1:100), acrescentando-se $1 \mathrm{ml}$ de hidróxido de sódio a $0,75 \mathrm{~N}$ e $1 \mathrm{ml}$ de ácido pícrico a $0,036 \mathrm{M}$ a solução. Foram seguidos os mesmos procedimentos descritos anteriormente para mensuração.

\subsubsection{Método FOX-2 para peróxidos urinários}

Os peróxidos são encontrados em todos os fluídos corporais, especialmente na urina. Alterações de seus níveis são consideradas como marcadores de geração de $\mathrm{H}_{2} \mathrm{O}_{2}$ ou preditores da extensão da lesão oxidativa in vivo ${ }^{(37)}$. A mensuração direta de peróxidos pode ser realizada através do método de análise FOX-2 ${ }^{(38)}$.

O método FOX-2 consiste na determinação dos níveis de peróxido através de método ferro-xilenol laranja. Os peróxidos são considerados como potenciais indicadores da formação ou resultantes das moléculas reativas de oxigênio ${ }^{(39)}$.

Os peróxidos oxidam o íon $\mathrm{Fe}^{2+}$ para íon $\mathrm{Fe}^{3+}$ quando diluídos em solução ácida, como descrita na reação abaixo:

$$
\mathrm{Fe}^{2+}+\mathrm{ROOH} \longrightarrow \mathrm{Fe}^{3+}+\mathrm{RO}+\mathrm{OH}^{-}
$$

O xilenol laranja [ácido (o-cresolsulfonaftalina 3', 3" - bis (metilamino) ácido diacético] apresenta alta seletividade para o íon $\mathrm{Fe}^{3+}$ produzindo um complexo de coloração azul-arroxeado $\left(\alpha=4,3 \times 10^{4} \mathrm{M}^{-1} \mathrm{~cm}^{-1}\right)^{39}$.

A preparação da solução obedeceu à seguinte ordem para realização do método de xilenol laranja versão - 2 (FOX-2):

- $90 \mathrm{ml}$ de metanol e $10 \mathrm{ml}$ de água bidestilada;

- 100 $\mu \mathrm{M}$ de xilenol laranja;

- 4mM de BHT (2[6] - di-ter-butil-p-cresol);

- 25mM da solução de ácido sulfúrico $\left(\mathrm{H}_{2} \mathrm{SO}_{4}\right)$;

- $250 \mu \mathrm{M}$ de sulfato ferroso de amônio-(Vetec Química- RJ, Brasil). 
A resultante da somatória dos reagentes acima consistiu na solução FOX. Na etapa seguinte, $100 \mu \mathrm{l}$ da amostra urinária fresca foi acrescentada em $900 \mu \mathrm{l}$ da solução FOX-2. A solução foi homogeneizada e permaneceu em repouso durante 30 minutos em temperatura ambiente. A leitura foi realizada por espectrofotometria em absorbância de 560nm, após a retirada de resíduos de proteínas ou outros materiais da centrifugação ${ }^{(39,40)}$.

Os valores foram estabilizados por grama de creatinina urinária e expressos por nmol de peróxidos/grama creatinina ${ }^{(41)}$.

\subsubsection{Dosagem de TBARS (Substâncias reativas com ácido tiobarbitúrico na urina)}

O MDA é um dos aldeídos freqüentemente analisados em métodos analíticos quantitativos e qualitativos para determinação dos índices de peroxidação lipídica e pode ser detectado por vários métodos dentre eles por meio da luz ultravioleta em sistema de cromoterapia de alta pressão (HPLC) e também com o uso do ácido tiobarbitúrico ao qual reage com várias substâncias dentre elas o MDA (TBARS) ${ }^{(42)}$.

A dosagem de TBARS na urina consiste na adição de $0,4 \mathrm{ml}$ da amostra de urina com $0,6 \mathrm{ml}$ de $\mathrm{H}_{2} \mathrm{O}$. Foram acrescentados nessa diluição 1,0ml de ácido tricloroacético (TCA) 17,5\% e 1,0ml de ácido tiobarbitúrico $(0,6 \% \mathrm{pH} 2)$, sendo que todos os tubos de ensaio com a solução foram mantidos no gelo durante essa primeira etapa do processo. A solução foi homogeneizada e depois colocada em água fervente (banho-maria) durante 20 minutos para reação com ácido tiobarbitúrico.

$\mathrm{Na}$ etapa seguinte a solução foi retirada do banho-maria, resfriada em gelo e adicionado $1,0 \mathrm{ml}$ de TCA $70 \%$. A solução foi homogeneizada e incubada por 20 minutos em tubo de ensaio tampado. Ao final, a solução foi centrifugada por 15 minutos a 3.000 r.p.m e a leitura foi realizada em espectrofotometria em absorbância de $534 \mathrm{~nm}{ }^{(43)}$.

A quantidade de MDA apresentada em nanomoles foi calculada usando o coeficiente de extinção molar $1,56 \times 10^{5} \mathrm{M}^{-1} \mathrm{~cm}^{-1}$. 
Os valores foram expressos em nmol de TBARS/grama de creatinina.

\subsubsection{Análise de tióis solúveis não protéicos no tecido renal}

O mais relevante composto tiólico presente em sistemas biológicos é a glutationa (GSH). A GSH está presente em todas as células e se constitui em principal tampão redox, onde suas funções biológicas estão centradas no grupamento tiól, presente na cadeia lateral que passa por repetidos ciclos de oxidação e redução. Dessa forma, a GSH se alterna entre sua forma reduzida (GSH - o tiól encontra-se na forma sulfidila livre) e a sua forma oxidada (GSSG - os tióis de duas moléculas de GSH condensam por uma ligação de dissulfeto). As altas concentrações de GSSG indicam desequilíbrio redox ou presença de lesão oxidativa. Portanto, a mensuração de tióis foi utilizada como indicador de estresse oxidativo, considerando o seguinte princípio: quanto maior o grau de estresse oxidativo, maiores serão os níveis de tióis oxidados e menores concentrações de tióis no tecido renal $^{(44)}$.

A quantificação dos tióis seguiu com a homogeneização do tecido renal dos animais dos diferentes grupos com $1 \mathrm{ml}$ de solução $10 \mathrm{nM}$ de acetato de sódio, 0,5\% tween-20 e $100 \mu \mathrm{M}$ DTPA (dietilenotriamina$\mathrm{N}, \mathrm{N}, \mathrm{N}$ ',N'-pentaacetato) em pH 6,5. O homogenato foi centrifugado a 5000 r.p.m por 10 minutos a $4^{\circ} \mathrm{C}$ para retirada de debris teciduais. Uma alíquota foi reservada para imediata mensuração de proteínas totais. A segunda alíquota foi precipitada com ácido tricloroacético a 10\% (1:1) e novamente centrifugada a 5000 r.p.m por 10 minutos a $4^{\circ} \mathrm{C}$. O sobrenadante foi utilizado para a mensuração de tióis totais.

O volume de $600 \mu \mathrm{l}$ das amostras precipitadas e diluídas foi homogeneizado em $300 \mu \mathrm{l}$ da solução com 1 mM de DTNB(5,5'-ditio-bis(2ácido nitrobenzoico) e $100 \mathrm{nM}$ de tampão Tris em pH 8,0. Após 10 minutos em temperatura ambiente, a quantidade de tióis foi determinada pela média da absorbância demonstrada em 412nm $\left(\alpha=13,6 \times 10^{3} \mathrm{M}^{-1} \mathrm{~cm}^{-1}\right)$. A leitura foi realizada em espectrofotômetro ${ }^{(45)}$. 
O equacionamento da mensuração de tióis solúveis foi ajustado para a contagem de proteínas total presentes no tecido renal que exigiu a mensuração de proteínas por meio do uso do kit Bio Rod, baseado no método Brad-ford, utilizando a albumina sérica bovina como padrão ${ }^{(46)}$.

Todos os valores obtidos foram estabilizados por nmol por $\mathrm{mg}$ de proteínas totais $^{(46)}$.

\subsubsection{Atividade da catalase no tecido renal}

A catalase é uma enzima amplamente distribuída em todos os tecidos e é constituída por quatro subunidades idênticas. A ferro-protoporfirina (hematina) é o maior componente ativo desta enzima, sendo responsável por catalisar a dismutação:

$$
2 \mathrm{H}_{2} \mathrm{O}_{2} \stackrel{\text { catalase }}{\longrightarrow} \mathrm{O}_{2}+2 \mathrm{H}_{2} \mathrm{O} \text {. }
$$

O princípio da mensuração da atividade da catalase $(A C)$ consiste na inativação da enzima durante a análise, em pequenas concentrações de $\mathrm{H}_{2} \mathrm{O}_{2}$ (10mM) que usualmente ocorre em trinta segundos, podendo ser também observada pela formação de bolhas na cubeta por liberação de oxigênio. A decomposição de $\mathrm{H}_{2} \mathrm{O}_{2}$ reduz da absorbância em 240nm e esta diferença por unidade é considerada a mensuração da atividade de catalase $^{(47)}$.

A AC está presente principalmente em tecidos renais e hepáticos. Nesse estudo o tecido renal foi homogeneizado com solução de PBS como descrito anteriormente. Uma alíquota foi retirada para dosagem de proteínas totais.

A preparação da solução para a mensuração da $A C$ utilizou $1 \mathrm{M}$ Tris$\mathrm{HCl}, 50 \mathrm{mM}$ EDTA (ácido etilenedinitrolo tetraacético) e $10 \mathrm{mM}$ de $\mathrm{H}_{2} \mathrm{O}_{2}$.

A leitura para a obtenção dos valores correspondentes à $A C$ foi realizada por espectrofotometria em absorbância em 240nm, acrescentandose $1 \mathrm{ml}$ da solução descrita em cubeta e a seguir $5 \mu \mathrm{l}$ da amostra. A leitura foi realizada em aproximadamente 2 minutos em temperatura ambiente ${ }^{(48)}$. 
Os valores foram estabilizados e expressos em nmol de $\mathrm{H}_{2} \mathrm{O}_{2}$ degradados por minutos/mg de proteínas totais ${ }^{(48)}$.

\subsubsection{Análise histológica e morfométrica}

Foram realizados estudos de morfometria para avaliação da expansão da área intersticial. As imagens obtidas pela microscopia óptica foram captadas por meio de vídeo-câmera de luz conectada a um analisador de imagens. Foram analisados 20 campos medindo $0,174 \mathrm{~mm}^{2}$ de cada animal e avaliada a fração percentual do córtex ocupado pelo interstício. Em seguida foi determinada a porcentagem da área intersticial em relação a cada campo, excluindo-se os glomérulos.

A leitura das lâminas foi realizada em microscópico óptico Axioskop 40 (Carl Zeiss, Jena, Alemanha).

\subsection{LOCAL}

Os experimentos descritos acima foram desenvolvidos no Laboratório Experimental de Modelos Animais (LEMA) da Escola de Enfermagem da Universidade de São Paulo - EEUSP, coordenado pela Prof $^{\underline{a}}$ Dr $^{\underline{a}}$ Maria de Fátima Fernandes Vattimo.

\subsection{ANÁLISE ESTATÍSTICA.}

Utilizou-se o método ANOVA, uma análise de variância a um fator, com intervalo de confiança para a média e comparação duas a duas. Os intervalos que continham sobreposição indicaram que os tratamentos eram iguais (e depois foi confirmado pelo teste de Tukey). Os resultados foram apresentados como média \pm erro padrão (SEM).

Os valores de $p<0,05$ foram considerados significantes. 


\section{Resultados}




\section{RESULTADOS}

\subsection{FUNÇÃO RENAL}

Tabela 1 - Resultados de peso corporal e função renal global dos grupos: Salina, Hemin, Protoporfirina de Zinco (ZnPP), PmxB, PmxB + Hemin, PmxB + ZnPP, PmxB + Hemin + ZnPP. São Paulo, 2008.

\begin{tabular}{lccccc}
\hline \multicolumn{1}{c}{ Grupos(n) } & $\begin{array}{c}\text { PC } \\
(\mathbf{g})\end{array}$ & $\begin{array}{c}\mathbf{U} \\
(\mathbf{m l} / \mathbf{m i n})\end{array}$ & $\begin{array}{c}\mathbf{C U} \\
(\mathbf{m g} / \mathbf{d l})\end{array}$ & $\begin{array}{c}\mathbf{C P} \\
(\mathbf{m g} / \mathbf{d l})\end{array}$ & $\begin{array}{c}\mathbf{C l c r} / \mathbf{1 0 0 g} \\
(\mathbf{m l} / \mathbf{m i n})\end{array}$ \\
\hline Salina (8) & $297 \pm 05$ & $0,0275 \pm 0,0404$ & $76,2 \pm 24,0$ & $0,22 \pm 0,06$ & $0,70 \pm 0,08$ \\
Hemin (6) & $296 \pm 16$ & $0,0084 \pm 0,0018$ & $108,5 \pm 38,9$ & $0,38 \pm 0,18$ & $0,81 \pm 0,15$ \\
ZnPP (7) & $291 \pm 25$ & $0,0064 \pm 0,0044$ & $89,3 \pm 25,3$ & $0,34 \pm 0,23$ & $0,54 \pm 0,12$ \\
PmxB (7) & $264 \pm 16^{\mathrm{ab}}$ & $0,0096 \pm 0,0091$ & $65,9 \pm 32,6$ & $0,52 \pm 0,06$ & $0,30 \pm 0,33^{\mathrm{abc}}$ \\
PmxB+Hemin (7) & $286 \pm 12$ & $0,0119 \pm 0,0059$ & $70,3 \pm 23,5$ & $0,54 \pm 0,19$ & $0,50 \pm 0,10^{\mathrm{ad}}$ \\
PmxB+ZnPP (6) & $284 \pm 18$ & $0,0155 \pm 0,0105$ & $35,4 \pm 29,3$ & $0,50 \pm 0,15$ & $0,28 \pm 0,14^{\mathrm{ace}}$ \\
PmxB+Hemin+ZnPP(4) & $284 \pm 22$ & $0,0092 \pm 0,0038$ & $48,4 \pm 16,1$ & $0,22 \pm 0,06$ & $0,66 \pm 0,08^{\mathrm{df}}$ \\
\hline
\end{tabular}

Sendo: PC-Peso corporal, U-Fluxo Urinário, CU-Creatinina Urinária, CP-Creatinina Plasmática e Clcr/100gClearance de Creatinina/100g.

${ }^{a} p<0,05$ vs Salina

b $p<0,05$ vs Hemin

${ }^{c} p<0,05$ vs $\mathrm{ZnPP}$

d $\mathrm{p}<0,05$ vs PmxB

${ }^{e} p<0,05$ vs PmxB+Hemin

${ }^{f} \mathrm{p}<0,05$ vs $P m \times B+Z n P P$

Os valores foram apresentados em média \pm erro padrão.

Conforme demonstrado na tabela 1, os animais não apresentaram variações significantes de peso corporal nos diversos grupos, com exceção do grupo PmxB que teve peso menor, porém ainda considerado dentro da normalidade para peso de rato adulto. O fluxo urinário também não apresentou variações significativas.

O grupo Salina apresentou valores de FR que possibilitaram a sua utilização como grupo controle para os demais animais, uma vez que os parâmetros estiveram de acordo com valores de normalidade adotados em estudos anteriores $^{(25,49)}$. Desse modo, quaisquer grupos que na comparação como esse resultaram em significância estatística para redução de Clcr foram considerados com LRA $(p<0,05)$. 
Os grupos controle Salina e Hemin não mostraram variabilidade significante quanto a FR $(0,70 \pm 0,08$ vs $0,81 \pm 0,15)$. Porém o grupo ZnPP demonstrou redução da FR em relação aos grupos Hemin e Salina $(0,54 \pm 0,12$ vs $0,70 \pm 0,08$ vs $0,81 \pm 0,15)$.

O pré-tratamento com $\mathrm{PmxB}$ por 5 dias resultou em redução significativa da FR caracterizando modelo de LRA por nefrotoxicidade $(0,30 \pm 0,33$ vs $0,70 \pm 0,08)$.

Observou-se que os animais tratados com PmxB e com o indutor da HO-1 (Hemin) apresentaram melhora significativa da FR quando comparado ao grupo $\mathrm{PmxB}(0,50 \pm 0,10$ vs $0,30 \pm 0,33)$. Em contra partida, o grupo PmxB que recebeu o inibidor de $\mathrm{HO}-1$ (ZnPP) respondeu com redução do Clcr quando comparado com o grupo PmxB+Hemin $(0,28 \pm 0,14$ vs $0,50 \pm 0,10)$.

Adicionalmente, a associação de indutor com inibidor de HO-1 no grupo tratado com $\mathrm{PmxB}$ desencadeou uma melhora da FR em relação aos tratamentos isolados $(0,66 \pm 0,08$ vs $0,50 \pm 0,10$ vs $0,28 \pm 0,14)$. 


\subsection{ESTRESSE OXIDATIVO}

\subsubsection{Peróxidos Urinários}

Tabela 2 - Resultados referentes aos valores de peróxidos urinários dos grupos: Salina, Hemin, Protoporfirina de Zinco (ZnPP), PmxB, PmxB + Hemin, PmxB + ZnPP, PmxB + Hemin + ZnPP. São Paulo, 2008

\begin{tabular}{lcc}
\hline Grupos & $\mathbf{n}$ & $\begin{array}{c}\text { Peróxidos urinários } \\
\text { (nmol/g de creatinina) }\end{array}$ \\
\hline Salina & 6 & $5,0 \pm 1,3$ \\
Hemin & 6 & $6,5 \pm 2,4$ \\
ZnPP & 6 & $5,4 \pm 3,3$ \\
PmxB & 5 & $35,6 \pm 9,9^{\mathrm{abc}}$ \\
PmxB+Hemin & 6 & $10,7 \pm 2,0^{\mathrm{d}}$ \\
PmxB+ZnPP & 6 & $24,4 \pm 12,5^{\mathrm{abce}}$ \\
PmxB+Hemin+ZnPP & 5 & $10,9 \pm 5,5^{\mathrm{df}}$ \\
\hline
\end{tabular}

\footnotetext{
${ }^{a} p<0,05$ vs Salina

${ }^{b} \mathrm{p}<0,05$ vs Hemin

${ }^{c} \mathrm{p}<0,05$ vs ZnPP

${ }^{d} p<0,05$ vs $P m \times B$

$\mathrm{p}<0,05$ vs PmxB + Hemin

${ }^{\dagger} \mathrm{p}<0,05$ vs PmxB + ZnPP

Os valores foram apresentados em média \pm erro padrão.
}

$\mathrm{Na}$ tabela 2 é possível verificar o grupo Salina apresentou resultados que foram considerados referência de normalidade para este parâmetro $(5,0 \pm 1,3)$.

Os grupos tratados com Hemin e ZnPP não mostraram variabilidade significativa quanto aos peróxidos urinários na comparação com o Salina $(5,0 \pm 1,3$ vs $6,5 \pm 2,4$ vs $5,4 \pm 3,3)$.

O grupo PmxB apresentou elevação significante nos valores de peróxidos urinários quando comparado ao controle Salina $(35,6 \pm 9,9$ vs $5,0 \pm 1,3)$.

O grupo tratado com PmxB e que recebeu pré-tratamento com Hemin demonstrou redução na excreção de peróxidos urinários (PU) na comparação com o grupo $\operatorname{PmxB}(35,6 \pm 9,9$ vs $10,7 \pm 2,0)$, porém, apesar 
disso, esse grupo não se equiparou aos valores do grupo Salina $(5,0 \pm 1,3$ vs $10,7 \pm 2,0)$. Diferentemente, os animais que receberam pré-tratamento com o inibidor ZnPP mostraram redução não estatisticamente significante dos PU na comparação com o grupo PmxB $(35,6 \pm 9,9$ vs $24,4 \pm 12,5)$.

A estratégia de associação do Hemin e ZnPP demonstrou efeito de redução na excreção de $\mathrm{PU}$ quando comparado com os animais $\mathrm{PmxB}$ e aqueles tratados com $\mathrm{PmxB}+\mathrm{ZnPP}(10,9 \pm 5,5$ vs $35,6 \pm 9,9$ vs $24,4 \pm 12,5)$.

\subsubsection{TBARS urinários}

Tabela 3 - Resultados referentes aos valores de TBARS urinários dos grupos: Salina, Hemin, Protoporfirina de Zinco (ZnPP), PmxB, PmxB + Hemin, PmxB + ZnPP, PmxB + Hemin + ZnPP. São Paulo - 2008

\begin{tabular}{lcc}
\hline Grupos & $\mathbf{n}$ & $\begin{array}{c}\text { TBARS urinários } \\
\text { (nmol/g de creatinina) }\end{array}$ \\
\hline Salina & 6 & $34,4 \pm 12,0$ \\
Hemin & 6 & $30,4 \pm 5,7$ \\
ZnPP & 6 & $48,5 \pm 11,4$ \\
PmxB & 6 & $98,1 \pm 35,7^{\mathrm{abc}}$ \\
PmxB+Hemin & 5 & $46,6 \pm 7,9^{\mathrm{d}}$ \\
PmxB+ZnPP & 5 & $60,0 \pm 22,6^{\mathrm{d}}$ \\
PmxB+Hemin+ZnPP & 5 & $60,2 \pm 21,7^{\mathrm{d}}$ \\
\hline
\end{tabular}

${ }^{a} p<0,05$ vs Salina

${ }^{b} p<0,05$ vs Hemin

$\mathrm{p}<0,05$ vs ZnPP

${ }^{d} p<0,05$ vs $P m \times B$

Os valores foram apresentados em média \pm desvio padrão.

A tabela 3 apresenta valores de TBARS urinários. Os resultados seguiram o padrão descrito para peróxidos urinários.

Novamente, os grupos controle Salina, Hemin e ZnPP não mostraram variabilidade estatística entre si $(34,4 \pm 12,0$ vs $30,4 \pm 5,7$ vs $48,5 \pm 11,36)$. O grupo ZnPP apresentou elevação nos valores de TBARS, contudo sem significância estatística $(48,5 \pm 11,36)$.

O grupo PmxB apresentou valores mais elevados de TBARS em relação ao grupo Salina $(34,4 \pm 12,0$ vs $98,1 \pm 35,7)$. 
O grupo PmxB+Hemin apresentou valores semelhante ao grupo Salina $(46,6 \pm 7,9$ vs $34,4 \pm 12,0)$, o que o diferenciou em muito do grupo PmxB $(98,1 \pm 35,7$ vs $46,6 \pm 7,9)$. Por outro lado, os grupos $\mathrm{PmxB}$ que receberam 0 tratamento com o inibidor de $\mathrm{HO}(\mathrm{ZnPP})$ e a associação de indutor e inibidor de $\mathrm{HO}$ (Hemin+ZnPP) apresentaram redução dos valores de TBARS urinários quando comparados com o grupo $\mathrm{PmxB}(60,0 \pm 22,6$ vs $60,2 \pm 21,7$ vs $98,1 \pm 35,7)$, mostrando valores de TBARS próximos ao do grupo PmxB+Hemin.

\subsubsection{Enzimas antioxidantes: Atividade da Catalase (AC) e tióis solúveis não protéicos no tecido renal.}

Tabela 4 - Resultados referentes à atividade de enzimas antioxidantes no tecido renal dos grupos: Salina, Hemin, Protoporfirina de Zinco (ZnPP), PmxB, PmxB + Hemin, PmxB + ZnPP, PmxB + Hemin + ZnPP. São Paulo 2008.

\begin{tabular}{lcccc}
\hline Grupos & $\mathbf{n}$ & $\begin{array}{c}\mathbf{A C} \\
\text { (nmol / } \mathbf{H}_{\mathbf{2}} \mathbf{O}_{\mathbf{2}} \text { degradados } \\
\text { / mg proteínas totais) }\end{array}$ & $\mathbf{n}$ & $\begin{array}{c}\text { Tióis } \\
\text { (nmol / mg de } \\
\text { proteínas totais) }\end{array}$ \\
\hline Salina & 3 & $5,6 \pm 1,2$ & 5 & $28,9 \pm 6,1$ \\
Hemin & 4 & $3,6 \pm 1,9$ & 4 & $26,3 \pm 17,6$ \\
ZnPP & 3 & $2,5 \pm 2,3$ & 4 & $19,2 \pm 5,4$ \\
PmxB & 3 & $1,2 \pm 0,4$ & 5 & $15,7 \pm 1,3$ \\
PmxB+Hemin & 4 & $3,4 \pm 1,0$ & 5 & $28,0 \pm 11,9$ \\
PmxB+ZnPP & 4 & $1,4 \pm 0,3$ & 5 & $21,0 \pm 9,4$ \\
PmxB+Hemin+ZnPP & 3 & $12,1 \pm 7,7^{\text {abcde }}$ & 4 & $28,6 \pm 20,3$ \\
\hline
\end{tabular}

Sendo $\mathrm{AC}$ - atividade da catalase

$\mathrm{a}<0,05$ vs Hemin

${ }^{b} \mathrm{p}<0,05$ vs ZnPP

${ }^{c} \mathrm{p}<0,05$ vs $\mathrm{PmxB}$

${ }^{d} p<0,05$ vs PmxB + Hemin

$\mathrm{p}<0,05$ vs PmxB + ZnPP

Os valores foram apresentados em média \pm desvio padrão.

A tabela 4 mostra que o tratamento com Hemin e ZnPP não determinou alteração significativa na $A C$ quando comparado com o grupo Salina. Por outro lado, a toxicidade do $\mathrm{PmxB}$ induziu redução tanto na $\mathrm{AC}$ quanto nos tióis seguindo na comparação com o controle Salina. $O$ tratamento com Hemin no grupo tratado com PmxB incrementou a atividade antioxidante em ambos os casos. O grupo PmxB+ZnPP demonstrou manutenção de AC e discreta elevação de tióis quando comparado com 
ZnPP e PmxB. Esses achados, apesar da evidente relevância biológica, não mostraram significância estatística.

A mensuração de enzimas antioxidantes resultou apenas em valores estatisticamente significantes para a $A C$ no grupo $P m x B$ que recebeu a associação do indutor e inibidor de $\mathrm{HO}$ (Hemin + ZnPP) quando comparado com todos os demais grupos.

A atividade enzimática no tecido renal dos diversos grupos acompanhou de forma complementar o perfil oxidativo apresentado dos PU e TBARS urinários. Lembrando que a atividade de enzimas antioxidantes é inversamente proporcional aos valores de hidroperóxidos e produtos resultantes da peroxidação lipídica da membrana celular (Gráfico 1).

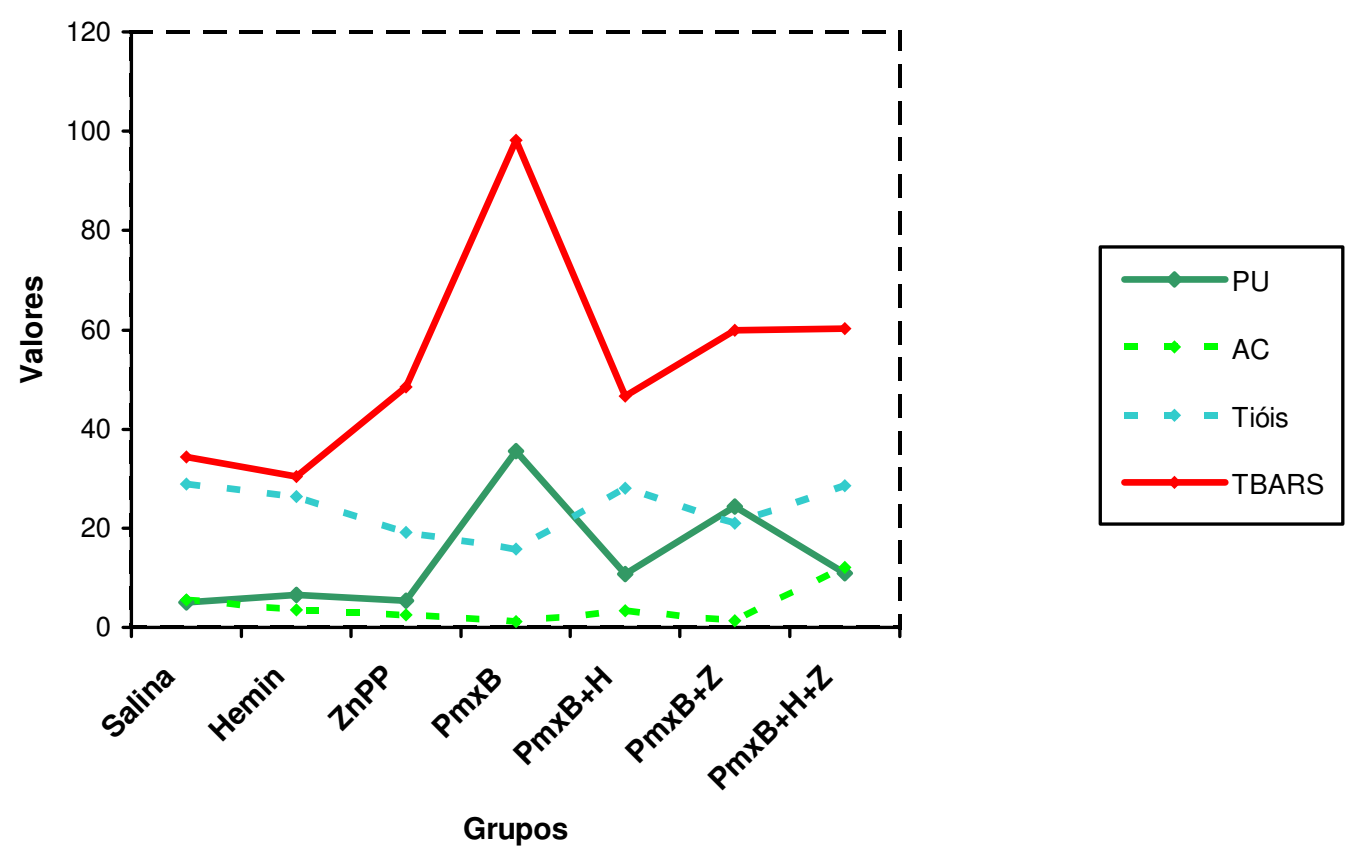

Gráfico 1 - Resultados referentes ao perfil oxidativo pelos métodos PU, AC, Tióis e TBARS dos grupos: Salina, Hemin, Protoporfirina de Zinco (ZnPP), PmxB, PmxB + Hemin, PmxB + ZnPP, PmxB + Hemin + ZnPP. São Paulo - 2008 


\subsection{ANÁLISE HISTOLÓGICA E MORFOMÉTRICA DO TECIDO RENAL}

Tabela 5 - Resultados referentes aos valores da área intersticial relativa (AIR) no tecido renal dos grupos: Salina, Hemin, Protoporfirina de Zinco (ZnPP), PmxB, PmxB + Hemin, PmxB + ZnPP, PmxB + Hemin + ZnPP. São Paulo, 2008

\begin{tabular}{lll}
\hline Grupos & $\mathbf{n}$ & \multicolumn{1}{c}{$\begin{array}{c}\text { AlR } \\
(\%)\end{array}$} \\
\hline Salina & 4 & $7,5 \pm 0,5$ \\
Hemin & 3 & $7,3 \pm 0,9$ \\
ZnPP & 3 & $11,9 \pm 1,3^{\mathrm{ab}}$ \\
PmxB & 4 & $10,0 \pm 1,0$ \\
PmxB+Hemin & 4 & $8,7 \pm 0,5^{\mathrm{c}}$ \\
PmxB+ZnPP & 5 & $10,4 \pm 1,5^{\mathrm{ab}}$ \\
PmxB+Hemin+ZnPP & 4 & $9,8 \pm 1,6$ \\
\hline
\end{tabular}

Sendo AIR-área intersticial relativa.

${ }^{a} p<0,05$ vs Salina

${ }^{b} p<0,05$ vs Hemin

${ }^{c} \mathrm{p}<0,05$ vs ZnPP

Os valores foram apresentados em média \pm desvio padrão.

Os resultados da tabela 5 referentes à análise morfométrica da área intersticial relativa no tecido renal demonstraram parâmetros semelhantes nos grupos Salina e Hemin $(7,5 \pm 0,5$ vs $7,3 \pm 0,9)$, enquanto que 0 grupo controle ZnPP apresentou estatisticamente maior AIR em relação ao grupo salina $(11,9 \pm 1,3$ vs $7,5 \pm 0,5)$.

O grupo PmxB demonstrou AIR superior ao controle. O pré tratamento com o indutor da HO-1 hemin no grupo tratado com PmxB resultou em menor AIR em relação aos grupos PmxB e ZnPP ( $8,7 \pm 0,5$ vs $10,0 \pm 1,0$ vs $11,9 \pm 1,3)$. O grupo PmxB+ZnPP mostrou maior AIR em relação aos grupos salina e equipqrou-se ao grupo $\operatorname{PmxB}(10,4 \pm 1,5$ vs $7,5 \pm 0,5$ vs $10,0 \pm 1,0)$. $O$ grupo PmxB+Hemin+ZnPP assemelhou-se aos grupos PmxB, PmxB+Hemin 
PmxB+ZnPP $\quad(9,8 \pm 1,6 \quad$ vs $10,0 \pm 1,0 \quad$ vs $8,7 \pm 0,5$ vs $10,4 \pm 1,5)$.

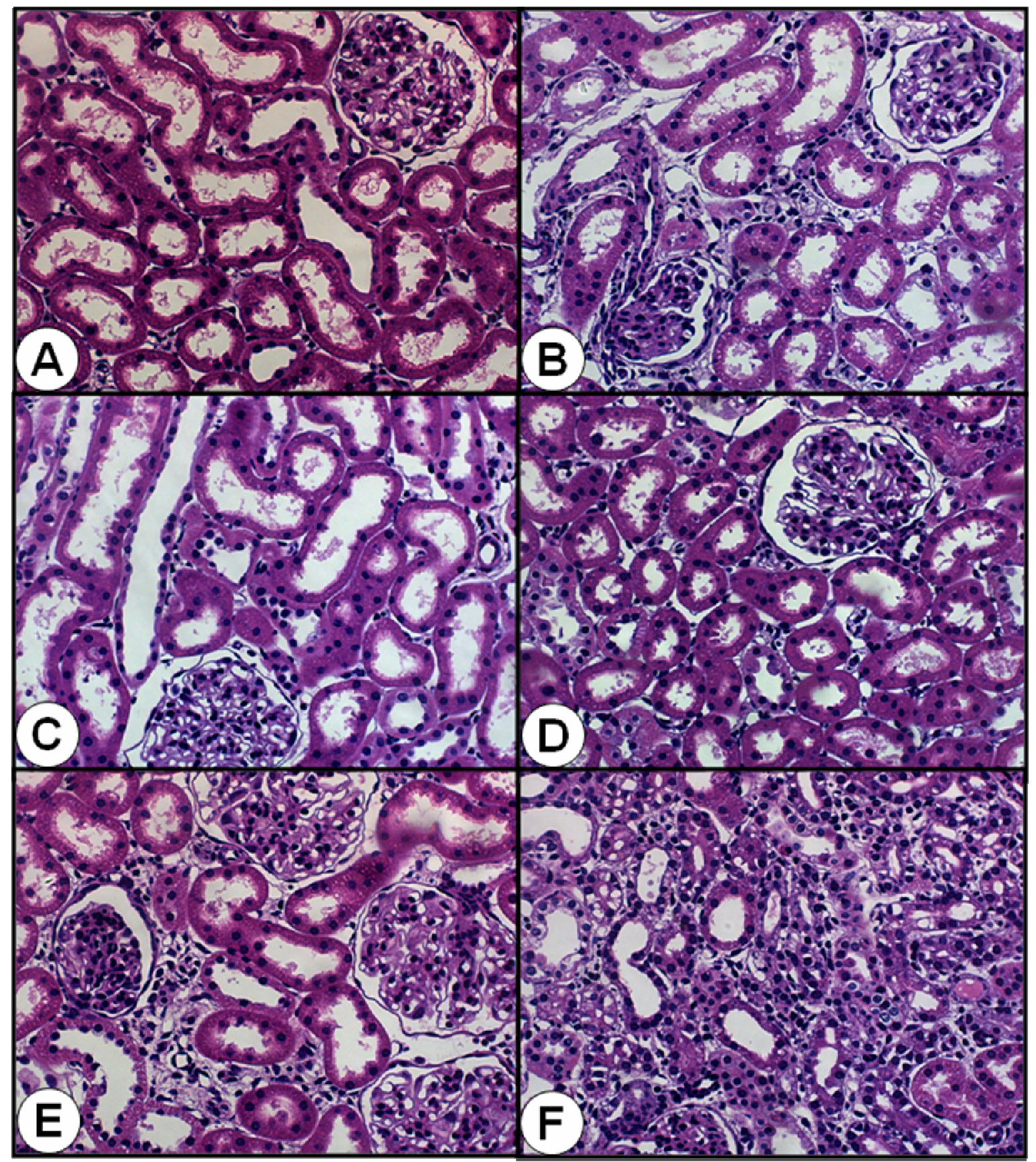

Figura 5 - Cortes histológicos no tecido renal dos diversos grupos: Salina (A); PmxB (B); Hemin (C); PmxB+Hemin(D); ZnPP (E) e PmxB+ZnPP (F).(Aumento 120x).

Não se constatou alterações de células tubulares nos achados histológicos dos grupos Salina (A) e Hemin (C).

Por outro lado, os resultados dos estudos histológicos dos grupos PmxB (B), ZnPP (E) e PmxB+ZnPP (F) evidenciaram a presença de lesões 
caracterizadas por edema e infiltrado inflamatório difuso do interstício, achatamento das células tubulares com dilatação da luz tubular, áreas focais de desnudamento da membrana basal e necrose tubular no córtex renal dos animais.

O pré-tratamento com o indutor da HO-1 no grupo $\mathrm{PmxB}+\mathrm{Hemin}$ (D) reduziu essas alterações de lesões tubulares. 


\section{DISCUSSÃO}

O retorno da utilização de drogas como o PmxB emergiu da mudança do perfil de resistência a infecções por microorganismos gram negativos freqüentemente encontrados em unidades de terapia intensiva. Nesses casos, a adoção de medidas farmacológicas muitas vezes se restringiu ao uso de polipeptídeos catiônicos como a PmxB. No entanto, seus efeitos adversos comprometem a persistência no tratamento.

A nefrotoxicidade de outros representantes dessa categoria de antimicrobianos já foi descrita, porém, pouco se sabe acerca dos mecanismos fisiopatológicos envolvidos na LRA pela PmxB.

A PmxB foi descoberta no final de 1947 quando sua eficácia no tratamento contra bactérias gram-negativas não foi questionada. Porém, seu uso foi gradualmente reduzido com o aparecimento de efeitos adversos principalmente nos sistemas renal e neurológico. O primeiro relato de nefrotoxicidade da polimixina data de 1983 e estava associado ao tratamento com colistina, a polimixina E, um dos seus seis compostos químicos ${ }^{(50)}$.

Atualmente, a nefrotoxicidade pela $\mathrm{PmxB}$ em pacientes graves é descrita em $20-40 \%$ dos $\operatorname{casos}^{(8)}$.

A HO-1 é uma enzima que pertence ao sistema Heme e que vem sendo estudada nos últimos anos em modelos experimentais como alternativa para prevenir a lesão oxidativa causada por isquemia ou agentes tóxicos renais.

Esta investigação teve por objetivo caracterizar o perfil fisiopatológico da lesão renal pela PmxB e avaliar a ação da enzima heme oxigenase-1 frente a essa lesão.

Foi possível constatar que o tratamento subcrônico com PmxB resultou em LRA não oligúrica em ratos adultos saudáveis. Esse efeito se comparou a outros exemplos farmacológicos de nefrotoxicidade como gentamicina, radiocontraste entre outros ${ }^{(25,49,51)}$. 
A redução da função renal nos animais que receberam o tratamento de PmxB por 5 dias pode pressupor o efeito desses peptídeos catiônicos com provável toxicidade tubular direta e alteração do mecanismo de concentração urinária resultando com o aumento da creatinina sérica, diminuição das atividades das enzimas antioxidantes e aumento da excreção de peróxidos e TBARS urinários.

O baixo suprimento energético celular na lesão nefrotóxica envolve a inibição do transporte molecular dependente de ATP com perda de íons gradientes e desorganização protéica intracelular que são mantidos pela polarização das membranas celulares epiteliais, regulando a ativação de sistemas enzimáticos como fosfolipases, proteases e alterações no cito esqueleto celular ${ }^{(1,2)}$. Esse evento de desorganização protéica intracelular e que pode preceder a morte celular é denominado desdiferenciação celular.

A depleção de ATP celular resulta ainda na liberação de EROs, as quais têm efeito devastador na lesão tóxica e isquêmica. A alta concentração de EROs origina a peroxidação lipídica, oxidação de proteínas celulares e lesão no DNA. Esses efeitos podem danificar a integridade das membranas plasmática e mitocondrial, comprometendo a função protéica e inibindo a proliferação e reparo celular ${ }^{(1)}$.

A manutenção da hipóxia favorece ainda o acúmulo de xantina, superóxido e peróxido de hidrogênio, os quais na presença do ferro livre geram o radical hidroxil que é altamente reativo. Concomitantemente, a indução da NO sintase nas células tubulares estimula a reação com o superóxido para formarem peroxidonitrito resultando em lesão celular com nitrolização das proteínas ${ }^{(12)}$.

Além disso, as EROs contribuem para a formação de mediadores vasoativos que induzem vasoconstrição com diminuição do coeficiente da ultrafiltração e redução da taxa de filtração. Esse evento é também intensificado pelo seqüestro de NO que agrega vasoconstrição à microcirculação renal, piorando a lesão renal ${ }^{(12)}$.

Em modelos de LRA tóxica foi observada uma vasoconstrição intrarenal e disfunção tubular com estabelecimento da NTA ${ }^{(52)}$. 
Os mecanismos responsáveis pela vasoconstrição intrarenal e hipoperfusão da medula externa não foram definidos completamente e envolvem múltiplos fatores. No entanto, há evidências que a endotelina seja um importante mediador da vasoconstrição e contribua para lesão tubular e insuficiência renal causada por isquemia e eventos tóxicos ${ }^{(1)}$. As EROs podem participar desse movimento, pois promovem a aderência de leucócitos e além de induzir agentes vasoconstritores como a endotelina que favorecem a formação de isoprostanos e tromboxanes e perpetuam a vasoconstrição. Os agonistas vasoconstritores podem não somente aumentar a resistência arteriolar renal, como também precipitar contração mesangial, que por sua vez, reduz o coeficiente de ultrafiltração glomerular e diminui a taxa de filtração glomerular. A vasoconstrição induzida via estresse oxidativo é relatada em várias formas de NTA nefrotóxica, incluindo lesão renal induzida por heme-proteínas em modelo de glicerol, sepsis induzida por NTA, vasoconstrição induzida por ciclosporina e nefropatia induzida por contraste e pode ter ocorrido também no modelo de toxicidade pela PmxB ora apresentado ${ }^{(2)}$.

Associada à alteração hemodinâmica na lesão oxidativa renal pela PmxB, a atividade das enzimas antioxidantes glutationa peroxidase e catalase acompanharam a excreção de peróxidos e TBARS urinários que neste estudo foram semelhantes à toxicidade descrita para gentamicina, em que se observou a redução da atividade da superóxido dismutase e glutationa peroxidase e em estudo com isquemia renal em que se constatou elevação de agentes oxidantes (MDA e peróxidos) e redução de $A C$ e tióis $^{(32,53)}$.

As enzimas antioxidantes contribuem para manutenção da homeostase celular em condições normais. Na LRA tóxica há um desequilíbrio entre a sua produção e a geração de radicais livres. Um deles é o radical hidroxila, um dos principais mediadores dessa lesão ${ }^{(12)}$.

Neste estudo foi observada elevação dos peróxidos e TBARS urinários nos animais tratados com $\mathrm{PmxB}$, o que confirma a atividade oxidativa provavelmente resultante da liberação do radical $\mathrm{OH}^{-}$. 
Mais recentemente, outros fatores como o oxido nítrico e o ânion peroxidonitrito têm sido reconhecidos pela capacidade de induzir lesão oxidante $^{(1)}$.

Estudos recentes demonstraram que a produção excessiva de NO mediado por iNOS causa estresse oxidativo com apoptose e lesão no DNA. Esse achado foi confirmado em modelos de nefrotoxicidade por gentamicina $^{(54)}$.

Em contrapartida a esses mecanismos de toxicidade, sabe-se que as células possuem "genes protetores", cuja expressão objetiva a preservação da estrutura e função celulares em ambientes nocivos. Um desses genes é o que codifica a heme oxigenase-1 (HO-1), uma enzima que degrada a molécula de heme, a qual tem papel fundamental em uma série de processos biológicos, como transporte de oxigênio, a respiração, a detoxificação de drogas e a transdução de sinal ${ }^{(55)}$.

A HO-1 é uma das três isoformas das heme oxigenases que são derivadas da molécula heme. A molécula heme se encontra freqüentemente associada a proteínas, entretanto, em diversas situações patológicas esta molécula pode se dissociar. Uma vez livre ou no meio intracelular, ela desestabiliza as membranas e pode catalisar a geração de radicais livres, reagindo com hidroperóxidos orgânicos ${ }^{(56)}$.

A HO não só controla os níveis celulares da síntese das heme proteínas, como também é responsável pela geração de bilirrubina, a qual é um importante antioxidante endógeno ${ }^{(57)}$. Em concentrações fisiológicas, a biliverdina é transformada em bilirrubina pela biliverdina redutase e assim se forma um ciclo de proteção antioxidante ${ }^{(58)}$. A HO-1 também aumenta a expressão de ferritina, que se associa ao ferro protegendo a célula do dano oxidativo e produz monóxido de carbono que age no processo antiinflamatório da lesão e também tem efeito vasodilatador ${ }^{(59,60)}$.

Neste estudo foi possível observar melhora da função renal com aumento do $\mathrm{Clcr}$ nos animais $\mathrm{PmxB}$ que receberam pré-tratamento com 0 hemin, indutor da HO-1. Além disso, se verificou diminuição na excreção dos 
peróxidos e TBARS urinários com normalização, ou aumento, da atividade da catalase e níveis de tióis.

Estudos recentes com modelos de indução de nefrotoxicidade por radiocontraste demonstraram que a indução de HO-1 com CoPP, protoporfirina de cobalto, foi associada à manutenção do ritmo de filtração glomerular, indicada pelo clearance de creatinina e níveis de creatinina plasmática normal. O pré-tratamento com CoPP diminuiu os níveis de heme e a formação de superóxido no rim e conseqüentemente aumentou a geração de bilirrubina e $\mathrm{CO}{ }^{(61)}$.

O tratamento crônico com ciclosporina em ratos demonstrou um aumento na formação de EROs no rim e revelou elevação da peroxidação lipídica via TBARS e redução dos níveis de glutationa (GSH/GSSG). Esse efeito foi relacionado com aumento da expressão gênica da HO-1 nos animais que receberam ciclosporina ${ }^{(62)}$.

Estudos revelaram ainda que em ratos diabéticos a indução de HO-1 aumentou a atividade da SOD e catalase e foi associado à redução do $\mathrm{O}_{2}$ Constatou-se também aumento da vasodilatação resultante da indução da eNOS ${ }^{(63)}$.

Em modelos de lesão renal por rabdomiólise se observou piora da função renal com a administração da protoporfirina de estanho (SnPP), inibidor seletivo da HO-1, enquanto que a indução promoveu redução da mortalidade ${ }^{(23)}$.

Em outros estudos de nefrotoxicidade induzida por cisplatina, a inibição da HO-1 pela SnPP determinou piora dos parâmetros funcionais e estruturais do tecido renal ${ }^{(24)}$.

Associado aos achados de FR, peróxidos, TBARS, catalase e tióis, este estudo demonstrou alterações histopatológicas subletais como edema de membrana, infiltrado inflamatório difuso do interstício com dilatação da luz tubular, com áreas de desnudamento da membrana basal e lesões representadas por necrose tubular aguda em alguns locais do córtex renal dos animais tratados com PmxB, ZnPP e PmxB+ZnPP. 
A associação de alterações de FR associada à elevação dos níveis de peroxidação lipídica é emblemática nos modelos de nefrotoxicidade. Os radicais livres de oxigênio aumentam a lesão lipídica da membrana e os peróxidos exacerbam as reações catalíticas desse componente celular. Isso gera desequilíbrio osmótico e aumenta o nível intracelular de cálcio. 0 edema celular é considerado um dos primeiros sinalizadores das lesões celulares reversíveis que podem ser detectados por microscopia óptica.

O simples aumento nos níveis de radicais livres como os peróxidos de hidrogênio determina o gatilho para o início de lesões estruturais reversíveis. A manutenção do desequilíbrio redox com ativação de enzimas lisossomais passam a manifestar lesões irreversíveis com pontos de necrose, como observado no presente estudo.

O uso de seqüestradores de EROs previne a lesão celular irreversível e a necrose. Certos tipos de sistemas enzimáticos e não enzimáticos inativam as reações oxidantes. Essas enzimas são as catalases, as superóxidos dismutases e a glutationa peroxidase. Neste estudo, a indução da HO-1 determinou elevação dessas enzimas refletindo efeito protetor funcional e estrutural nos animais tratados com PmxB.

Dessa forma, de acordo com os achados bioquímicos e patológicos desse estudo, pode se afirmar que a indução da HO-1 revelou efeito protetor da lesão celular degenerativa do tratamento com PmxB com resposta funcional e histológica.

Outros estudos sobre nefrotoxicidade da gentamicina e cisplatina demonstraram resultados semelhantes ${ }^{(24,28)}$.

Sumariamente, 0 estudo confirmou o efeito nefrotóxico do polipeptídeo catiônico, a polimixina $B$, com manutenção de fluxo urinário, à semelhança de diversos outros relatos de toxicidade farmacológica. Além disso, constatou-se que o desequilíbrio redox é mecanismo pró-ativo nessa lesão, com nítida elevação de agentes oxidantes e redução de reserva antioxidante endógena com repercussão na histologia renal. 
Ressalta-se que os fármacos continuam a ser origem comum de lesão renal aguda. Comparado com 30 anos atrás, o paciente de hoje é mais velho, tem mais co-morbidades e está exposto a mais procedimentos terapêuticos e diagnósticos com maior potencial nefrotóxico como a PmxB. A nefrotoxicidade tende a ser mais comum em certos pacientes e situações, contudo, a prevenção de sucesso exige o conhecimento dos mecanismos patogênicos da lesão renal e a adoção de medidas pré-emptivas, como pode vir a representar a interferência no sistema heme oxigenase.

Assim, os achados deste estudo foram providentes na medida em que definiram o perfil dessa lesão, contudo, investigações que avaliem os genes citoprotetores e a sinalização intracelular, entre outros, na vigência do tratamento com fármacos, em muito contribuirão para 0 melhor esclarecimento dos mecanismos fisiopatológicos da lesão renal pela PmxB. 


\section{Conclusões}




\section{CONCLUSÕES}

- O tratamento com PmxB reduziu a função renal dos ratos.

- O pré-tratamento com o indutor da HO-1 promoveu melhora da função renal dos ratos tratados com PmxB, enquanto que a inibição da HO-1 pelo ZnPP reduziu esse parâmetro.

- A indução da HO-1 aumentou atividade da catalase e glutationa e diminuiu a excreção de peróxidos urinários e TBARS, enquanto que a inibição demonstrou efeito oposto, ou seja, elevação de PU e TBARS e redução de $A C$ e tióis.

- A análise histológica demonstrou que a associação do PmxB com o inibidor ZnPP aumentou a área de infiltrado inflamatório, promovendo edema, achatamento das células tubulares com pontos de necrose no córtex renal. 


\section{Referências}




\section{REFERÊNCIAS}

1. Molitoris BA. Acute Renal Failure: cellular Basis of Ischemic Acute Renal Failure. In: Brenner BM. The Kidney. $6^{\text {th }}$ ed. Philadelphia, WB Saunders Company; 2000.v.1. p.1-4.

2. Brady HR, Brenner BM, Clarkson MR, Lieberthal W. Acute Renal Failure: Acute Tubule Necrosis. In: Brenner BM. The Kidney. $6^{\text {th }}$ ed. Philadelphia: WB Saunders Company; 2000.v.1. p.1201-1232.

3. Shimizu H, Takahashi T, Suzuki T, Yamasaki A, Fujiwara T, Odaka Y, et al. Protective effect of heme oxygenase induction in ischemic acute renal failure. Crit Care Med. 2000; 28(3): 809-817.

4. Uchino S. The epidemiology of actue renal failure in the world. Curr Opin Crit Care. 2006; 12:538-543.

5. Pannu N, Nadim MK. An overview of drug-induced acute kidney injury. Crit Care Med. 2008; 36(4):216-223.

6. Uchino S, Kellum JA, Bellomo R, Doig GS, Morimatsu H, Morgera S, et al. Actue renal failure in critically ill patients: A multinational, multicenter study. JAMA. 2005; 294:813-818.

7. Mehta RL, Pascual MT, Soroko S. et al. Spectrum of acute renal failure in the intensive care unit: The PICARD experience. Kidney Int. 2004; 66:1613-1621.

8. Falagus ME, Kasiakou SK. Toxicity of Polymyxins: a systemic review of the evidence from old and recent studies. Critical Care. 2006; 10(1): 113.

9. Arnold TM, Forrest GN, Messmer KJ. Polymyxin antibiotics for gramnegative infections. Am J Health-Syst Pharm. 2007; 64(15): 819-26.

10. Ouderkirk JP, Nord JA, Turett GS, Kislak JW. Polymyxin B Nephrotoxicity and Efficacy against Nosocomial Infection caused by Multiresistent gram-negative bacteria. Antimicrobial Agents and Chemotherapy. 2003; 08: 2659-62. 
Cassiane Dezoti

11. Omri A, Suntres ZE, Shek PN. Enhanced activity of liposomal polymyxin $B$ against Pseudomonas Aeruginosa in rat model of lung infection. Biochemical Pharmacology. 2000; 64: 1407-13.

12. Nath KA, Norby SM. Reactive oxygen species and acute renal failure. Am J Med. 2000; 109(8): 665-78.

13. Devarajan P. Update on Mechanisms of Ischemic Acute Kidney Injury. J Am Soc Nephrol. 2006; 17:1503-1520.

14. Okusa MD. The inflammatory cascade in acute ischemic renal failure. Nephron. 2002; 90(2):133-8.

15. Nordberg J, Arner ESJ. Reactive oxygen species, antioxidant, and the mammlian thioredoxin system. Free Rad Biol and Med. 2001; 31(11): 1287-312.

16. McCord JM. The evolution of free radical and oxidative stress. Am J Med. 2000; 108(8):652-9.

17. Sener G, Sener E, Sehirli O, Ogunç AV, Cetinel S, et al. Ginkgo biloba extract ameliorates ischemia reperfusion-induced renal injury in rats. Pharmacological Research. 2005; 52:216-22.

18. Durante W, Kroll MH, Christodoulides N, Peyton KJ, Schafer AL. Nitric oxide induces heme oxygenase-1 gene expression and carbon monoxide production in vascular smooth muscle cells. Circ Res. 1997; 80(4):557-64.

19. Kumar S, Bandyopadhaway U. Free heme toxicity and its detoxification systems in human. Toxicol Lett. 2005; 157(3): 175-88.

20. Sikorski EM, Hock T, Hill-Kapturczak N, Agarwal A. The story so far: molecular regulation of the heme oxygenase-1 gene in renal injury. Am J Phydiol Renal Physiol. 2004; 286(3):F425-41.

21. Agarwall A, Nick HS. Renal response to tissue injury: lessons from heme oxygenase-1 gene ablation and expression. J Am Soc Nephrol. $2000 ; 11(5): 965-73$. 
22. Morimoto K, Ohta K, Yachie A, Yang Y, Shimizu M, Goto C, et al. Cytoprotective role of heme oxygenase-1 (HO-1) in human kidney with various renal diseases. Kidney Int. 2001; 60(5):1858-66.

23. Nath KA, Balla G, Varcellotti GM, Balla J, Jacob HS, Levitt MD, et al. Induction of response in a rhabdomyolysis in the rat. J Clin Invest. 1992; 90(1): 267-70.

24. Agarwal A, Balla J, Alam J, Croatt AJ, Nath KA. Induction of heme oxygenase in toxic renal injury: a protective role in cisplatina nephrotoxicity in the rat. Kidney Int. 1995; 48(4): 1298-307.

25. Pinto CF, Vattimo MFF, Watanabe M. Hydration and n-acetylcysteine in acute renal failure caused by iodated contrast: an experiment in rats. JNephrol. 2008; 21:783-788.

26. Peyrou M, Hanna PE, Cribb AE. Cisplatin, Gentamicin, and pAminophenol Induce Markers of Endoplasmic Reticulum Stress in Rat Kidneys. Toxicological Sciences. 2007; 99(1):346-53.

27. Kadkhodaee $M$, Khastar $H$, Arab HA, Ghaznavi R, Zahmatkesh $M$, Mahdavi-Mazdeh M. Antioxidant vitamins preserve superoxido dismutase activities in gentamicin-induced nephrotoxicity. Transplantation Proceedings. 2007; 39:864-65.

28. Ghaznavi R, Kadkhodaee M. Comparative effects of seletive and nonselective nitric oxide synthase innibition in gentamicin-induced rat nephrotoxicity. Arch Toxicol. 2007; 81: 453-57.

29. Sayed-Ahmed MM, Nagi MN. Thymoquinone supplementation prevents the development of gentamicin-induced actue renal toxicity in rats. Clinical and Experimental Pharmacology and Physiology. 2007; 34: 399-405.

30. Goodman A, Olszanecki R, Yang LM, Quan S, Li M, et al. Heme oxygenase-1 protects against radiocontrast-induced acute kidney injury by regulating anti-apoptotic proteins. Kidney International. 2007; 72: 945-53. 
Cassiane Dezoti

31. Nath KA, Haggard JJ, Croatt AJ, et al. The indispensability of heme oxygenase-1 in protecting against acute heme protein-induced toxicity in vivo. Am J Pathol. 2000; 156:1527-1535.

32. Watanabe M, Neiva LMB, Santos CCX, Laurindo FM, Vattimo MFF. Isoflavone and the heme oxygenase system in Ischemic acute kidney injury in rats. Food Chem Toxicol. 2007; 45(12):2366-2371.

33. Neiva LBM, Watanabe M, Santos OFP. Toxicity of polymyxin on $\mathrm{LLCPK}_{1}$ cells can be mediated by heme oxygenase-1? In: Book Abstracts World Congress of Nephrology; 2007; Rio de Janeiro, BR. Rio de Janeiro; 2007. p. 524.

34. Holzen JP, August C, Bahde R, Minin E, Lang D, et al. Influence of Heme Oxygenase-1 on Microcirculation After Kidney Transplantation. Journal of Surgical Research. 2008; 148:126-135.

35. Miyazano M, Garat C, Morris KG Jr, Carter EP. Decreased renal heme oxygenase-1 expression contributes to decreased renal function during cirrhosis. Am J Physiol Renal Physiol. 2002; 283(5):F1123-31.

36. Dorea EL, Yu L, De Castro I, Campos SB, Ori M, Vaccari EM, et al. Nephrotoxicity of amphotercin $B$ is attenuated by solubilizing with lipid emulsion. J Am Soc Nephrol. 1997; 8(9): 1415-22.

37. Hill-Kapturczak N, Chang SH, Agarwal A. Heme oxygenase and the kidney. DNA Cell Biol. 2002; 21(4):307-21.

38. Halliwell B, Gutteridge JMC, editors. Free radical in biology and medicine. $3^{\text {rd }}$ ed. New York: Oxford University Press; 1999. Antioxidants protection by low-molecular-mass agents: compounds derived from the diet; p. 200-30.

39. Gay C, Collins J, Gebicki JM. Hydrogen peroxide assay with the ferricxylenol orange complex. Anal Biochem. 1999; 273(2):149-55.

40. Wolff SP. Ferrous íon oxidantion in presence of ferric íon indicator xylenol orange for mensurament of hydroperoxides. Methods Enzymol. 1994; 233:182-9. 
41. Banerjee D, Madhusoodanan UK, Nayak S, Jacob J. Urinary Hydrogen peroxide: a probably marker of oxidative stress in malignancy. Clin Chim Acta. 2003; 334 (1/2):205-9.

42. Lima ES, Abdalla DSP. Peroxidação lipídica: mecanismos e avaliação em amostras biológicas. Brazilian Journal of Pharmaceutical Sciences. 2001; 37(3): 293-303.

43. Walker PD, Shah SV. Reactive oxygen metabolites in endotoxininduced actue renal failure in rats. Kidney Int. 1990; 38:1125-32.

44. Filomeni G, Rotilio G, Ciriolo MR. Cell signaly and the glutathione redox system. Biochem Pharmacol. 2002; 64:1057-64.

45. Akerboom TPM, Sies H. Assay glutathione, glutathione disulfide, and glutathione mixed disulfides in biological samples. Methods Enzymol. $1981 ; 77: 373-82$.

46. Read SM, Northcote DH. Minimization of the response to different protein of the coomassie blue $G$ dye-binding assay for protein. Anal Biochem. 1981; 116(1): 53-64.

47. Aebi H. Catalase in vitro. Methods Enzymol. 1984; 105:121-6.

48. Kamura N. Catalase. In: Taniguchi N, Gutteridge JMC, editors. Experimental protocols for reative oxygen and nitrogen species. London: Oxford Universy Press;2000.p.77-9.

49. Martim ECO, Pinto CF, Watanabe M, Vattimo MFF. Acute Kidney Injury by glycerol: antioxidant effect of Vitis Vinifera L. Rev. Bras. Ter. Intensiva. 2007; 19(3):292-96.

50. Dallery C. Polymyxin B (sulphate). In: Dollery C, editor. Therapeutic drugs. Edwinburg: Churcill Livinstore; 1991. p. 151-4.

51. Hosaka EM, Santos OFP, Seguro AC, Vattimo MFF. Effect of cyclooxygenase inhibitors on gentamicin-induced nephrotoxicity in rats. Brazilian Journal of Medical and Biological Research. 2004; 37:979-985. 
52. Fujigaki $Y$, Sakakima $M$, Sun $Y$, Goto $T$, Ohashi $N$, et al. Immunohistochemical study on caveolin-1a in regenerating process of tubular cells in gentamicin-induced acute tubular injury in rats. Virchows Arch. 2007; 450:671-681.

53. Velasco-velazquez MA, Maldonado PD, Barrera D, Torres V, ZentellaDehesa A, Pedraza-Chaverri J. Aged Garlic extract induced proliferation and ameliorate gentamicin-induced toxicity in LLC-PK 1 cells. Phytother. Res. 2006; 20:76-8.

54. Goligorosky MS, Gross SS. Nitric oxide and the kidney. New York: Chapman e Hall 1997, p.22-38.

55. Azambuja P, D’Avila J. Heme Oxigenase-1. In: David CM, Faria-Neto HCC. Sepse da bancada à beira do leito. Rio de Janeiro: Revinter; 2007. v. 13, p. 147-53.

56. Gallucci S, Malzinger P. Danger signals: SOS to the immune system. Curr Opin Immunol. 2001; 13:114-9.

57. Stocker R, Glazer AN, Ames BN. Antioxidant activity of albumin-bound bilirrubin. Proc Natl Acad Sci USA. 1987; 84:5918-22.

58. Baranano DE, Rao M, Ferris CD. Biliverdin reductase: a major physiology cytoprotectant. Proc Natl Acad Sci USA. 2002; 99:16093-8.

59. Balla G, Jacob HS, Balla J, Rosenberg M, Nath K, Apple F, et al. Ferritin: a cytoprotective antioxidant stratagem of endothelium. J Biol Chem. 1992; 267(25):18148-53.

60. Ryter SW, Alam J, Choi AMK. Heme Oxygenase-1/Carbon Monoxide: From Basic Science to Therapeutic Applications. Physiol Rev. 2006; 86:583-650.

61. Dore S, Takahashi M, Ferris CD, Zakhary R, Hester LD, Guastella D, et al. Bilirrubin, formed by activaction of heme oxygenase-2, protects neurons against oxidative stress injury. Proc Natl Acad Sci USA. 1999;96(5):2445-50. 
62. Capasso G, Gennaro DID, Ragione FD, Manna C, Ciarcia R, Florio S, et al. In vivo effect of the natural antioxidant hydroxytyrosol on cyclosporine nephrotoxicity in rats. Nephrol Dial Transplant. 2008;23(4):1186-95.

63. Turkseven S, Kruger A, Mingone CJ, Kaminski P, et al. Antioxidant mechanism of heme oxygenase- 1 involves an increase in superoxide dismutase and catalase in experimental diabetes. Am J Physiol Heart Circ Physiol. 2005; 289:H701-707. 


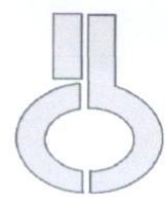

\section{Certificado}

Certificamos que o protocolo registrado sob $\mathrm{n}^{\circ} \mathbf{0 3 8}$ nas fls. $\mathbf{5 6}$ do livro 02 para uso de animais em experimentação, sob a responsabilidade de Maria de Fatima Fernandes Vattimo, Coordenador(a) da Linha de pesquisa "Nefrotoxicidade do sulfato de polimixina $B(P M B)$ em ratos e a enzima Heme-Oxigenase-1 (HO- 1$)^{\prime \prime}$ do qual participou(aram) o(s) alunos Cassiane Dezoti está de acordo com os Princípios Éticos de Experimentação Animal adotado pelo Colégio Brasileiro de Experimentação Animal (COBEA) e foi aprovado pela COMISSÃO DE ÉTICA EM EXPERIMENTAÇÃO ANIMAL (CEEA) em 27.06.08, com validade de 3 anos.

São Paulo, 27 de junho de 2008.

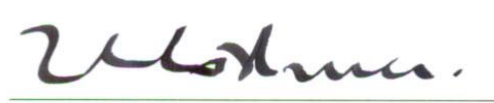

Prof. Dr. Wothan TAVARES DE LIMA Coordenador CEEA - ICB/USP

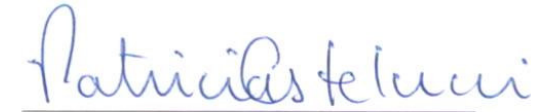

Profa. Dra. PATRÍCIA CASTElUCCI Secretária CEEA - ICB/USP 